\title{
Repurposing Tranexamic Acid as an Anticancer Agent
}

Mary E. Law ${ }^{1}$, Bradley J. Davis ${ }^{1}$, Amanda F. Ghilardi ${ }^{2}$, Elham Yaaghubi ${ }^{2}$, Zaafir M. Dulloo ${ }^{2}$, Mengxiong Wang ${ }^{1}$, Olga A. Guryanova ${ }^{1,3}$, Coy D. Heldermon ${ }^{3,4}$, Stephan C. Jahn ${ }^{1}$, Ronald K. Castellano ${ }^{2,3}$ and Brian K. Law ${ }^{1,3 *}$

${ }^{1}$ Department of Pharmacology and Therapeutics, University of Florida, Gainesville, FL, United States, ${ }^{2}$ Department of Chemistry, University of Florida, Gainesville, FL, United States, ${ }^{3}$ UF Health Cancer Center, University of Florida, Gainesville, FL, United States, ${ }^{4}$ Department of Medicine, University of Florida, Gainesville, FL, United States

Tranexamic Acid (TA) is a clinically used antifibrinolytic agent that acts as a Lys mimetic to block binding of Plasminogen with Plasminogen activators, preventing conversion of Plasminogen to its proteolytically activated form, Plasmin. Previous studies suggested that TA may exhibit anticancer activity by blockade of extracellular Plasmin formation. Plasmin-mediated cleavage of the CDCP1 protein may increase its oncogenic functions through several downstream pathways. Results presented herein demonstrate that TA blocks Plasmin-mediated excision of the extracellular domain of the oncoprotein CDCP1.

Edited by: Hany Omar,

University of Sharjah, United Arab Emirates

Reviewed by: Patrick M. Woster, Medical University of South Carolina United States

Chandra C. Ghosh, Beth Israel Deaconess Medical Center and Harvard Medical School, United States

${ }^{*}$ Correspondence: Brian K. Law bklaw@ufl.edu

Specialty section: This article was submitted to Pharmacology of Anti-Cancer Drugs, a section of the journal

Frontiers in Pharmacology

Received: 10 October 2021 Accepted: 30 November 2021

Published: 13 January 2022

Citation:

Law ME, Davis BJ, Ghilardi AF, Yaaghubi E, Dulloo ZM, Wang $M$,

Guryanova $O A$, Heldermon $C D$, Jahn SC, Castellano RK and Law BK (2022) Repurposing Tranexamic Acid as an Anticancer Agent.

Front. Pharmacol. 12:792600. doi: 10.3389/fphar.2021.792600 In vitro studies indicate that TA reduces the viability of a broad array of human and murine cancer cell lines, and breast tumor growth studies demonstrate that TA reduces cancer growth in vivo. Based on the ability of TA to mimic Lys and Arg, we hypothesized that TA may perturb multiple processes that involve Lys/Arg-rich protein sequences, and that TA may alter intracellular signaling pathways in addition to blocking extracellular Plasmin production. Indeed, TA-mediated suppression of tumor cell viability is associated with multiple biochemical actions, including inhibition of protein synthesis, reduced activating phosphorylation of STAT3 and S6K1, decreased expression of the MYC oncoprotein, and suppression of Lys acetylation. Further, TA inhibited uptake of Lys and Arg by cancer cells. These findings suggest that TA or TA analogs may serve as lead compounds and inspire the production of new classes of anticancer agents that function by mimicking Lys and Arg.

Keywords: MYC, S6K1, CDCP1, STAT3, protein synthesis, acetylation, tranexamic acid, cancer

\section{INTRODUCTION}

Repurposing FDA-approved drugs as anticancer agents represents a powerful method for rapidly advancing new cancer therapeutics into the clinic especially since many of the safety issues are already established. This is particularly true for a drug like Tranexamic Acid (TA), which is on The WHO List of Essential Medicines and has an excellent safety record while being widely used for over 50 years in a broad range of formulations and dosages in numerous different indications. TA is clinically used to suppress hemorrhaging by blocking Plasminogen conversion to Plasmin. TA functions as a Lys side chain mimetic and prevents Plasmin formation by occupying Lys binding sites on Plasminogen (Iwamoto 1975). Due to its ability to mimic the side chains of Lys, and perhaps Arg, yet not being incorporated into protein due to its structure, TA has the potential to alter many biological processes. For instance, basic amino acid residues are present in the nuclear import signals of proteins (Laskey et al., 1996) and in the consensus recognition sites of many protein kinases, most 
noteworthy, the AGC family of serine/threonine kinases (Zhang et al., 2002). Additionally, Lys side chains in proteins are subject to multiple posttranslational modifications that include acetylation, methylation, ubiquitination, and SUMOylation. The "histone code" of epigenetic regulation involves Lys and Arg modifications (Turner 2000; Izzo and Schneider 2010; Tweedie-Cullen et al., 2012; Blee et al., 2015). Given the important role of Lys and its modifications in the control of multiple cellular processes, we hypothesized that in addition to its widespread use to suppress bleeding, TA may inhibit the enzymes that carry out Lys modification in proteins in a competitive manner, suppress the function of Lys/Arg-rich protein-protein recognition motifs, or compete with the transporters that mediate Lys/Arg uptake.

While TA has been used to manage cancer and cancer treatment-associated sequela in patients (Soma et al., 1980; Kikuchi et al., 1986; Oertli et al., 1994; Wu et al., 2006; Longo et al., 2018; Lohani et al., 2020; Jaffer et al., 2021; Lohani et al., 2021), it has never been used clinically as an anti-cancer therapeutic, and considerations of TA anticancer actions have focused on its blockade of Plasmin production. The goals of the studies carried out herein were three-fold: 1 . To examine the impact of TA treatment on the viability of cancer cells to evaluate the possibility of repurposing TA as an anticancer agent, 2. To determine if TA may provide a lead compound to serve as the basis of derivatives with greater anticancer efficacy and potency, and enhanced selectivity for specific downstream responses, and 3. Because of its unusual mechanism of action, test whether TA may prove useful in combination anticancer regimens. Given our previous work with a class of anticancer compounds termed Disulfide bond Disrupting Agents (DDAs) (Ferreira et al., 2015; Ferreira et al., 2017; Besse et al., 2019; Wang et al., 2019a; Wang et al., 2019b) and observations below that TA and DDAs have partially overlapping biochemical mechanisms of action, we evaluated the anticancer activity of TA and DDA mono- and combination therapies in an animal model of breast cancer. The results show that TA suppresses the viability of a broad array of human and murine cancer cell lines, exhibits previously unreported effects on cell signaling pathways that control cancer cell proliferation and oncogenic transformation, and modulates the acetylation status of Lys residues in a subset of acetylated proteins. TA and the DDAs tcyDTDO and dMtcyDTDO strongly suppress the growth of breast tumors individually and may be useful in combination.

\section{MATERIALS AND METHODS}

\section{MTT Cell Viability Assays}

MTT cell viability assays were performed by plating cells at 7,500/ well in 96-well plates, followed by treatment of the cells with increasing concentrations of TA (Chem-Impex International, Inc., Wood Dale, IL, United States) for $72 \mathrm{~h}$ at $37^{\circ} \mathrm{C}$. After removal of the cell media, cells were incubated with $0.5 \mathrm{mg} / \mathrm{ml}$ MTT (3-(4,5-dimethylthiazol-2-yl)-2,5-diphenyltetrazolium bromide) (Biomatik, Wilmington, DE, United States) in PBS for $3 \mathrm{~h}$. The MTT solution was subsequently removed and the MTT formazan product was dissolved in $100 \mu \mathrm{l}$ of DMSO. Absorbance (570 and $690 \mathrm{~nm}$ ) of the MTT formazan product was measured in a plate reader.

\section{Tumor Studies}

012/LVM2/LR10 tumors were generated by injection of $1 \times 10^{6}$ 012/LVM2/LR10 cells into the \#4 mammary fat pads of NODSCID-gamma (NSG) mice from Jackson Laboratories (Bar Harbor, ME, United States), as described previously (Wang et al., 2019b). In the tumor study in Figures 1F,G, mice bearing HCI-012/LVM2/LR10 breast tumors were treated once daily with $375 \mathrm{mg} / \mathrm{kg}$ TA by oral gavage for 12 days followed by breast tumor removal. In the tumor study in Figure 4A, tumors were generated using the $012 / \mathrm{LVM} 2 / \mathrm{LR} 10$ cancer cell model as above and the animals were treated with vehicle (peanut oil), $375 \mathrm{mg} / \mathrm{kg}$ TA in water, $10 \mathrm{mg} / \mathrm{kg}$ dMtcyDTDO in peanut oil, or $375 \mathrm{mg} / \mathrm{kg}$ TA $+10 \mathrm{mg} / \mathrm{kg}$ dMtcyDTDO once daily by oral gavage. Tumor dimensions were recorded daily at the time of treatment.

\section{Protein Synthesis Assays}

Protein synthesis assays were performed by measurement of the incorporation of ${ }^{3} \mathrm{H}$-Leucine (Perkin Elmer, Waltham, MA, United States) into protein, as detailed previously (Law et al., 2000a; Law et al., 2000b).

\section{Thymidine Incorporation Assays}

Thymidine incorporation assays were described in a previous publication (Corsino et al., 2009).

\section{Cellular Uptake of Lys and Arg}

MDA-MB-468 cells were plated at $10^{5} /$ well in 24 well plates and incubated overnight to permit attachment. Cells were gently washed with PBS and fed with serum-free and Arg and Lysfree DMEM (Thermo Fisher, Waltham, MA, United States, Cat. \# 88364 ) containing the indicated concentrations of TA and incubated for $24 \mathrm{~h}$. Cells were pulsed for $2 \mathrm{~h}$ with $0.5 \mu \mathrm{Ci} /$ well ${ }^{3} \mathrm{H}$-Arg (PerkinElmer, Waltham, MA, United States, Cat. \# NET1123250UC) or $0.2 \mu \mathrm{Ci} /$ well ${ }^{14} \mathrm{C}$-Lys (PerkinElmer, Cat. \# NEC280E050UC). The cells were washed twice with PBS and lysed in $300 \mu \mathrm{l} /$ well $0.1 \%$ SDS in $0.5 \mathrm{~N} \mathrm{NaOH}$. Uptake of radiolabeled amino acids was quantified by counting $100 \mu \mathrm{l}$ of the lysate from each well in a scintillation counter.

\section{P300 Acetylation Assays}

P300 Acetylation assays were performed by incubating the reaction buffer (50 mM Tris, $\mathrm{pH} 8.0,10 \%$ glycerol, $0.1 \mathrm{mM}$ EDTA, and $1 \mathrm{mM}$ DTT), $0.5 \mu \mathrm{g}$ p300 (ENZO Life Sciences, Farmingdale, NY, United States), $0.5 \mu \mathrm{g}$ Histone H3 (NEB, Ipswich, MA, United States), and $60 \mu \mathrm{M}$ Acetyl CoA (SigmaAldrich, St. Louis, MO, United States) in the presence or absence of TA, NacTA, or tcyDTDO for $2 \mathrm{~h}$ at $30^{\circ} \mathrm{C}$. Reactions were terminated by the addition of $2 \mathrm{X}$ SDS sample buffer and boiling for $10 \mathrm{~min}$, followed by immunoblot analysis employing a 45 min transfer to $0.2 \mu \mathrm{m}$ nitrocellulose using CAPS buffer, $\mathrm{pH} 11$. 
A

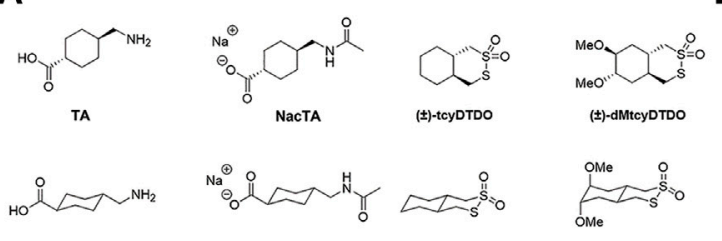

B
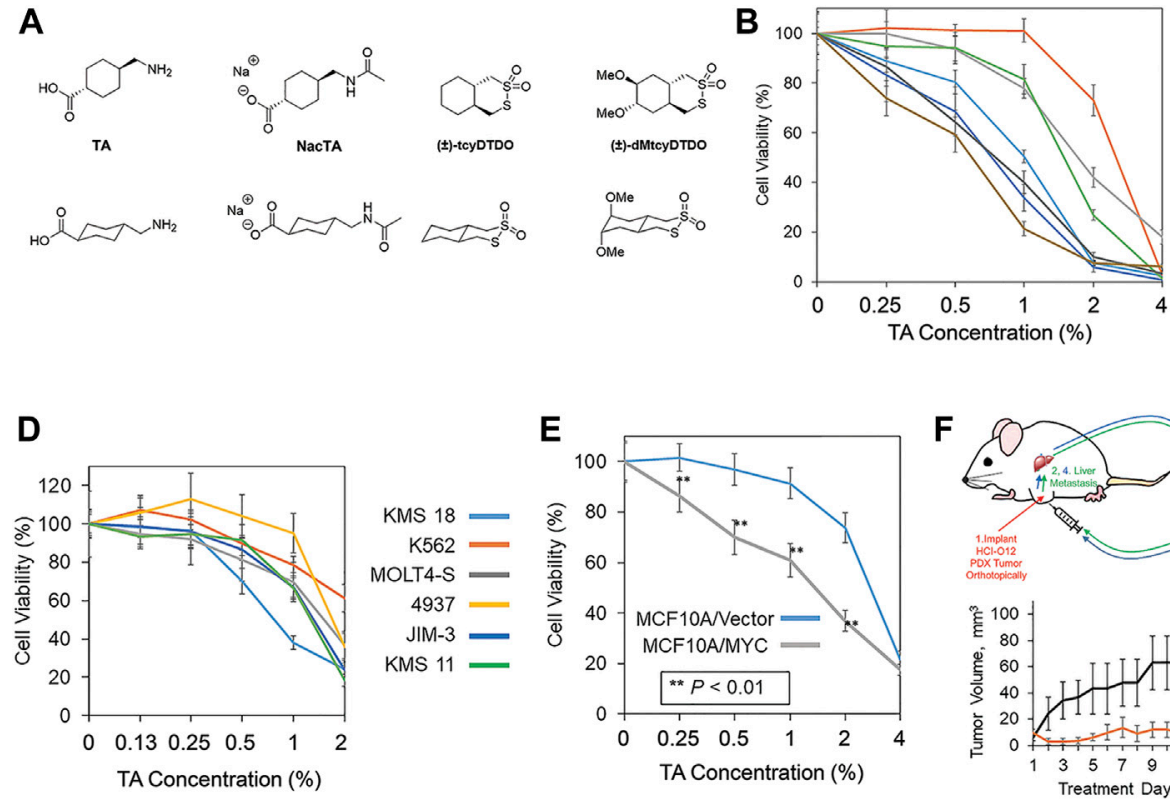

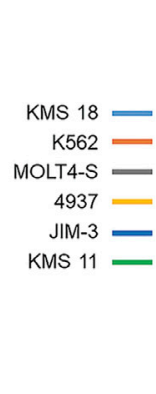

E
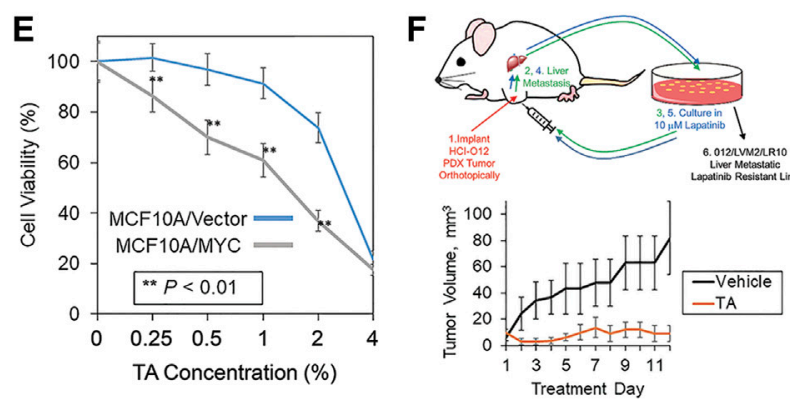

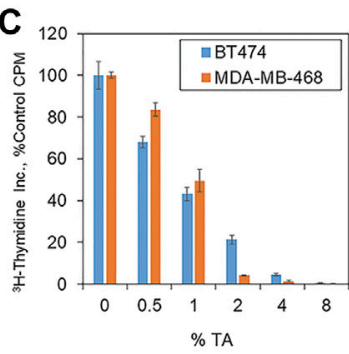

G

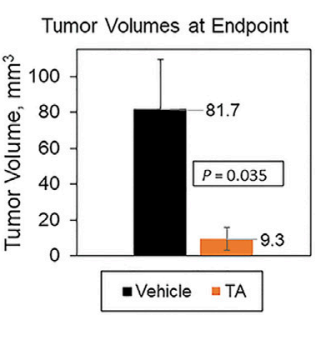

FIGURE 1 | TA decreases cancer cell viability and breast tumor growth. (A) Chemical structures of TA, N-acetylated TA (NacTA), and the DDAs tcyDTDO and dMtcyDTDO. (B) The indicated panel of cancer cell lines were treated for $72 \mathrm{~h}$ with different TA concentrations and cell viability was measured using the MTT assay. Results are the average of six replicates and presented as the average \pm S.D. These findings are representative of three biological replicates with similar results. (C) MDAMB-468 and BT474 cells were treated for $24 \mathrm{~h}$ with the indicated concentrations of TA and the incorporation of tritiated thymidine into DNA was evaluated. Results are the average of six replicates and presented as the average \pm S.D. These findings are representative of three biological replicates with similar results. (D) Effects of TA on the viability of a panel of leukemia, lymphoma, and multiple myeloma cell lines. Results are the average of six replicates and presented as the average $\pm S$.D. These findings are representative of three biological replicates with similar results. (E) Cell viability assay showing that TA more potently reduces the viability of MCF10A mammary epithelial cells overexpressing MYC compared with the vector control line. Statistically significant differences between the lines were observed at $0.25,0.5,1$, and $2 \%$ TA. $p$-values were calculated using unpaired Student's $t$-tests. Results are the average of six replicates and presented as the average \pm S.D. These findings are representative of three biological replicates with similar results. (F) Tumor growth study in which mice bearing orthotopic 012/LVM2/LR10 mammary tumors were treated once daily with $375 \mathrm{mg} / \mathrm{kg}$ TA. The upper panel illustrates how the 012/LVM2/LR10 cancer model was derived. Tumor dimensions were measured daily and tumor volumes calculated. Averages of within-group tumor volumes are presented and error bars represent standard error of the mean. (G) Tumor volumes measured at day 12 exhibit a statistically significant TA-mediated reduction in tumor volume $(p=0.035)$, with an approximately nine-fold smaller tumor volume in the TA group than the vehicle group. $p$-values were calculated using an unpaired Student's $t$-test. Each treatment group contained five animals.

\section{NacTA Synthesis General Methods}

Reagents and solvents were purchased from commercial sources without further purification unless otherwise specified. ${ }^{1} \mathrm{H}$ and ${ }^{13} \mathrm{C}$ NMR spectra were recorded using commercially obtained $\mathrm{D}_{2} \mathrm{O}$ (Cambridge Isotope Laboratories, Inc.) on a Bruker 600 spectrometer $\left({ }^{1} \mathrm{H}\right.$ at $\left.600 \mathrm{MHz}\right)$ and Bruker 400 spectrometer $\left({ }^{13} \mathrm{C}\right.$ at $101 \mathrm{MHz}$ ), respectively. Chemical shifts $(\delta)$ are given in parts per million (ppm) relative to TMS and referenced to residual protonated $\mathrm{D}_{2} \mathrm{O}(\delta \mathrm{H}=4.79 \mathrm{ppm})$. Coupling constants $(J)$ are given in $\mathrm{Hz}$; spin multiplicities are presented by the following symbols: s (singlet), bs (broad singlet), d (doublet), $\mathrm{t}$ (triplet), $\mathrm{q}$ (quartet), and $\mathrm{m}$ (multiplet). Electrospray ionization (ESI) high resolution mass spectra (HRMS) were recorded on an Agilent 6200 ESI-TOF instrument operating in positive or negative ion mode as stated.

\section{Synthesis of Sodium (1r,4r)-4-(Acetamidomethyl) Cyclohexane-1-Carboxylate, NacTA}

The preparation of NacTA was adapted from a procedure reported by Kusakabe et al. (2010). Tranexamic acid (1.90 g, $12.1 \mathrm{mmol})$ was suspended in acetic anhydride $(9.70 \mathrm{ml}$,
$103 \mathrm{mmol}$ ) and concentrated $\mathrm{H}_{2} \mathrm{SO}_{4}(5.00 \mu \mathrm{l})$ was carefully added. The suspension was stirred for $18 \mathrm{~h}$ at rt. Water $(10.0 \mathrm{ml})$ was added and the mixture was stirred for $1 \mathrm{~h}$ at $\mathrm{rt}$ to decompose any remaining acetic anhydride. The solution was concentrated under vacuum, and the residue was further dried with the addition of toluene and subsequent removal of solvent under reduced pressure. The resulting precipitate was collected by vacuum filtration and washed with ethyl ether to give NacTA as a white powder. For the sodium salt preparation, NacTA was suspended in water and an aqueous solution of $2 \mathrm{M} \mathrm{NaOH}$ was added with stirring at $\mathrm{rt}$ until the $\mathrm{pH}$ increased to 13 . The suspension was then stirred for an additional $1 \mathrm{~h}$ at $\mathrm{rt}$ until the entire solid dissolved. The solvent was then evaporated under reduced pressure and the precipitate was recrystallized in ethanol to remove remaining $\mathrm{NaOH}$ salt. The white precipitate obtained was then collected by vacuum filtration and washed with ethanol to afford the product as a white solid $(1.30 \mathrm{~g}, 5.80 \mathrm{mmol}, 48 \%$ yield). ${ }^{1} \mathrm{H}$ NMR $\left(600 \mathrm{MHz}, \mathrm{D}_{2} \mathrm{O}\right) \delta 3.01(\mathrm{~d}, J=6.8 \mathrm{~Hz}, 2 \mathrm{H}), 2.08$ $(\mathrm{tt}, J=12.2,3.5 \mathrm{~Hz}, 1 \mathrm{H}), 1.98(\mathrm{~s}, 3 \mathrm{H}), 1.90-1.84(\mathrm{~m}, 2 \mathrm{H}), 1.77$ (dd, $J=13.2,3.6 \mathrm{~Hz}, 2 \mathrm{H}), 1.52-1.42(\mathrm{~m}, 1 \mathrm{H}), 1.31(\mathrm{qd}, J=13.0,3.7 \mathrm{~Hz}$, $2 \mathrm{H}), 0.96(\mathrm{qd}, J=12.8,3.6 \mathrm{~Hz}, 2 \mathrm{H})$. The $\mathrm{NH}$ proton was not observed. ${ }^{13} \mathrm{C}$ NMR $\left(101 \mathrm{MHz}, \mathrm{D}_{2} \mathrm{O}\right) \delta 186.50,173.97,46.92$, 
45.53, 36.78, 29.49, 29.23, 21.80. HRMS-ESI: $m / z[\mathrm{M}]^{-}$calcd for $\left[\mathrm{C}_{10} \mathrm{H}_{16} \mathrm{NO}_{3}\right]^{-}:$: 198.1136; found: 198.1148 .

\section{Cell Culture, Preparation of Cell Extracts, and Immunoblot Analysis}

The BT474, MDA-MB-231, MDA-MB-468, MCF10A, HMEC, B16, MALME-3M, DU145, SH-SY5Y, K 562, and MOLT4 cells lines were purchased from American Type Culture Collection (ATCC) (Manassas, VA USA). The KMS-11, KMS-18, JIM-3, and 4937 cell lines were kindly provided by Dr. Olga Guryanova, University of Florida Health Cancer Center and the WM793 cell line was generously provided by Dr. W. Douglas Cress, Moffitt Cancer Center. Derivation of the HCI-012/LVM2/LR10 cell line was previously described (Wang et al., 2019a; Wang et al., 2019b). MCF10A cell lines stably expressing MYC were generated as detailed in previous reports (Law et al., 2002; Wang et al., 2019a; Wang et al., 2019b), as was the generation of the 231/ E-Cad and 231/E-Cad-GFP cells lines (Law et al., 2013). Cell lysates were prepared, as described previously (Law et al., 2002). The antibodies used for immunoblot analyses are listed in Supplementary Table S1.

\section{In Silico Molecular Docking}

Compounds were docked into the Arg binding pocket of the bacterial homolog of CAT (CATh). The crystal structure was downloaded from the RCSB protein databank (Accession \# 6f34, (Jungnickel et al., 2018)) in .pdb format and all heteroatoms were removed. The molecular surface of the protein was created using the Chimera program and spheres representing potential docking sites were created using SPHGEN. Spheres that did not correspond to the Arg binding pocket were removed and the SHOWBOX program created a 3-dimensional box around the spheres with a $4 \AA$ buffer on all sides. The GRID program was then used to generate files representing the electrostatic and van der Waals forces produced by the protein in the region of interest. The DOCK program was used to calculate GRID scores for the ligands of interest, consisting of electrostatic and van der Waals interactions, and ranked depending on predicted binding affinity. All programs were from UCSF and, except for Chimera, are included in the DOCK 6.7 suite (Allen et al., 2015). Images were generated using PyMol from Schrodinger.

\section{Statistical Analysis}

\section{Statistics}

Statistical analysis was performed using the unpaired Student's $t$-test. Error bars represent standard deviation of the mean unless otherwise indicated and all $p$ values are two-tailed. $p$ values are documented in either the figures or legends. Points from cell culture studies plotted on bar or line graphs are the average of six or more replicates and are representative of three or more independent experiments. Quantitation of immunoblot results was performed by scanning the blots, inverting the images with Photoshop (San Jose, CA, United States), and quantitating band intensities using Image (NIH). Bar graphs of band intensities are presented as the average and error bars correspond to the standard error of the mean.

\section{RESULTS}

\section{Tranexamic Acid Suppresses Cancer Cell Viability In Vitro and Tumor Growth In Vivo} Chemical structures of TA and the other compounds used or mentioned in the work described here are shown in Figure 1A. MTT cell viability assays showed that TA suppressed the viability of a variety of cancer cell lines including melanoma (B16, WM793, and MALME-3M), breast (MDA-MB-468 and BT474), prostate (DU145), and neuroblastoma (SH-SY5Y) lines (Figure 1B). DU145 was one of the more TA-sensitive lines and exhibited statistically significant TA-mediated viability suppression at the lowest TA concentration tested $0.25 \%(\mathrm{w} / \mathrm{v})$ compared with the vehicle control (Supplementary Figure S1A). Analysis of TA effects on cell proliferation, as measured by ${ }^{3} \mathrm{H}$-thymidine incorporation, showed that TA inhibited DNA synthesis in the BT474 and MDA-MB-468 cells over the same concentration range that it reduces cell viability (Figure 1C). Studies of TA effects on the viability of leukemia, lymphoma, and multiple myeloma lines using the XTT assay showed concentration-dependent reductions in cancer cell viability (Figure 1D). The MYC oncogene is frequently overexpressed in human cancers (Rothberg 1987; Saksela 1990; Shiu et al., 1993). However, MYC overexpression renders cancer cells vulnerable to some therapeutics, resulting in collateral vulnerabilities amenable to synthetic lethal targeting approaches (Hsieh and Dang 2016; Lee et al., 2019). Therefore, we examined if MYC overexpression increased the sensitivity of the MCF10A human breast epithelial cell line to TA. MYC overexpression enhanced the TA suppression of cell viability across an array of TA concentrations suggesting that MYC overexpression may be useful as a marker to identify TA-sensitive tumors (Figure 1E).

We employed a previously described metastatic, Lapatinibresistant, orthotopic xenograft model, 012/LVM2/LR10 (Wang et al., 2019a; Wang et al., 2019b), to examine if TA reduces the growth of breast tumors in experimental animals (Figure 1F, upper panel). Tumor growth studies revealed that $375 \mathrm{mg} / \mathrm{kg}$ TA suppressed the growth of $012 / \mathrm{LVM} 2 / \mathrm{LR} 10$ tumors without evidence of treatment toxicity (Figure 1F, lower panel). At the 12-day treatment endpoint, tumors in the TA treatment group were approximately one-ninth the size of the tumors in the vehicle group (Figure 1G).

\section{TA Suppresses S6K1 and STAT3 Phosphorylation}

We next sought to examine the mechanisms through which TA impacts tumor growth. TA may exhibit anticancer activity through effects on Plasmin activity and via Plasminindependent actions (O'Grady et al., 1981; Tanaka et al., 1982; Stonelake et al., 1997; Dunbar et al., 2000; Suojanen et al., 2009). Previous work indicated that Plasmin cleaves the extracellular domain of the transmembrane protein CUB Domain-Containing Protein $1(\mathrm{CDCP} 1)$ to produce a truncated protein that exhibits differential protein-protein interactions and signaling functions compared with the full-length protein, suggesting that cleaved CDCP1 (cCDCP1) may contribute to tumor growth and 


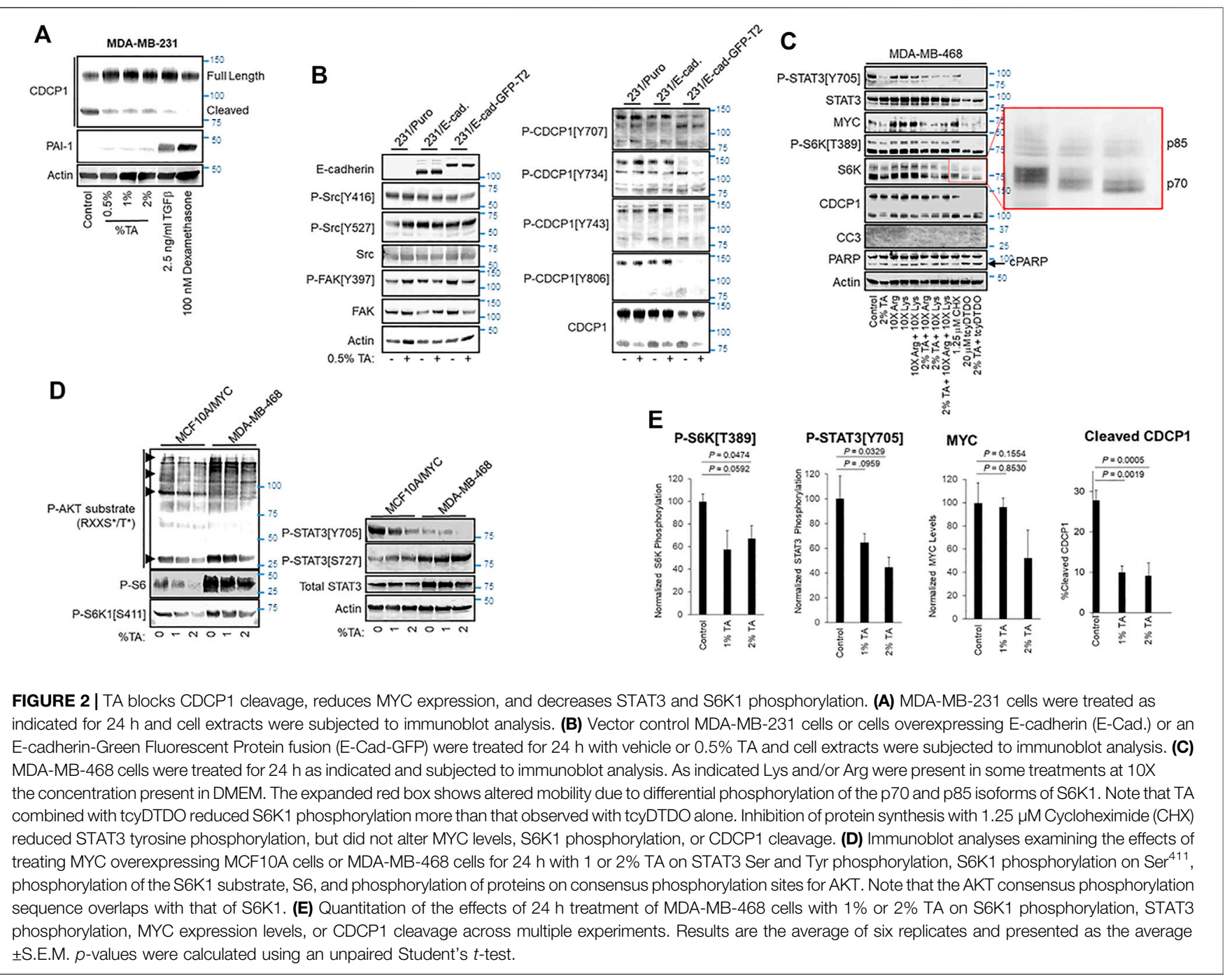

progression (Casar et al., 2014; Law et al., 2016; Wright et al., 2016). However, the ability of TA to suppress CDCP1 cleavage has not been examined. TA reduced CDCP1 cleavage in MDAMB-231 breast cancer cells (Figure 2A). Unlike Transforming Growth Factor- $\beta$ (TGF $\beta$ ) or the glucocorticoid dexamethasone, which block CDCP1 cleavage by upregulating Plasminogen Activator Inhibitor-1 (PAI-1) (Law et al., 2013; Law et al., 2016), TA did not increase PAI-1 levels (Figure 2A). cCDCP1 binds E-cadherin and interferes with its cell-cell adhesive functions, while the full-length protein does not (Law et al., 2016). Blocking CDCP1 cleavage via TA administration may be useful on restoring the anti-invasive functions of E-cadherin. Since full-length CDCP1 does not bind E-cadherin, we did not expect enforced E-cadherin expression to alter TA inhibition of CDCP1 cleavage positively or negatively. To test this, we examined if enforced expression of E-cadherin or an E-Cadherin-Green Fluorescent Protein (GFP) fusion protein influences TA blockade of CDCP1 cleavage (Figure 2B). TA $(0.5 \% \mathrm{w} / \mathrm{v})$ decreased CDCP1 cleavage in MDA-MB-231 cells irrespective of E-cadherin overexpression and did not significantly impact CDCP1 tyrosine phosphorylation on multiple sites previously implicated in regulating downstream signaling proteins including Src (He et al., 2010; Liu et al., 2011). Consistent with this, TA did not alter Src phosphorylation on activating (Y416) or inhibitory (Y527) sites (Figure 2B). FAK and CDCP1 exhibit reciprocal tyrosine phosphorylation patterns in which FAK is heavily phosphorylated in cells attached to substrata, while CDCP1 is heavily phosphorylated in cells growing in suspension (Wortmann et al., 2011). TA did not alter FAK phosphorylation on the Y397 site that reflects FAK activation (Thamilselvan et al., 2007). Both the full length, $135 \mathrm{kDa}$, and cleaved, $85 \mathrm{kDa}$, forms of CDCP1 exhibited tyrosine phosphorylation at multiple sites.

We also screened the effects of TA on several other signaling pathways important in tumor growth and progression including the oncogenic transcription factors STAT3 and MYC, the mitogen-activated serine/threonine kinases S6 protein kinase (S6K), ERK, and AKT, and the levels and phosphorylation status of proteins that control cell cycle progression including Cyclin D1, Cyclin B1, and cleavage of PARP and Caspase 3 as 
markers of apoptotic cell death. TA reduced STAT3 tyrosine phosphorylation on its activating site, Y705, decreased MYC protein expression, and suppressed S6K1 phosphorylation on the activating site, T389 (Figure 2C). TA reduction of cell viability in MTT assays closely paralleled suppression of proliferation in thymidine incorporation assays (see Figures 1B,C). Consistent with this observation, TA did not increase the apoptotic markers Cleaved Caspase 3 (CC3) or PARP cleavage. However, tcyDTDO increased CC3 to detectable levels and elevated PARP cleavage as expected. TA had no consistent effect on ERK or AKT phosphorylation, Cyclin D1 or Cyclin B1 levels, or PARP or Caspase 3 cleavage across the MDA-MB-468, BT474, and WM793 human cancer cell lines (Supplementary Figure S1B).

TA treatments were also carried out in the presence of $10 \mathrm{X}$ excesses of Lys or Arg to examine the ability of high levels of these amino acids to overcome TA effects. High Lys or Arg levels did not alter STAT3 phosphorylation, but increased S6K1 phosphorylation and MYC levels consistent with the sensitivity of S6K1 activation (Iiboshi et al., 1999; Hidayat et al., 2003) and MYC expression (Yue et al., 2017) to amino acid levels (Figure 2C). However, TA still reduced S6K1 phosphorylation and MYC levels in the presence of excess Lys or Arg. Treatment with the protein synthesis inhibitor cycloheximide (CHX) was included as a control to determine if inhibition of protein synthesis was sufficient to mimic any TA effects. CHX decreased STAT3 phosphorylation, but did not decrease MYC levels or S6K1 phosphorylation. Control protein synthesis experiments showed that $1.25 \mu \mathrm{M}$ CHX inhibits protein synthesis by approximately 60\% (Supplementary Figure S1C).

Our group identified a class of compounds with anticancer activity termed DDAs that interfere with disulfide bond formation, induce endoplasmic reticulum (ER) stress, and inhibit protein synthesis (Ferreira et al., 2015; Ferreira et al., 2017; Wang et al., 2019a; Wang et al., 2019b). Results posted in a preprint suggest that DDAs act by inhibiting a subset of Protein Disulfide Isomerases (Law et al., 2021). Therefore, we examined if DDAs induce overlapping responses with TA and therefore may be useful in combination regimens against cancer. The DDA tcyDTDO decreased STAT3 and S6K1 phosphorylation and MYC levels (Figure 2C). Combined tcyDTDO/TA treatment reduced overall S6K1 phosphorylation more than either treatment alone as evidenced by electrophoretic mobility shifts of both the 70 and $85 \mathrm{kDa}$ forms of S6K1 (Figure 2C, expanded region). We next examined the effect of TA on the phosphorylation of STAT3 and S6K1 in the MCF10A human mammary epithelial cell line overexpressing MYC and the MDAMB-468 breast cancer line. TA induced a concentrationdependent decrease in STAT3 phosphorylation on Y705 but had no effect on phosphorylation on S727 (Figure 2D). The AGC-family kinases AKT and S6K1 have similar Arg-rich consensus substrate recognition sequences. Immunoblot analyses using antibodies recognizing phospho-AKT substrates and the S6K1 substrate S6 showed a TA-induced decrease in phosphorylation at these sites. This was paralleled by reduced phosphorylation of the S6K1 site S411 that is also associated with kinase S6K1 activation (Han et al., 1995). Together, the results discussed thus far in Figure 2 indicate that TA inhibits a subset of mitogenic/oncogenic signaling pathways. Quantification studies demonstrated that $2 \% \mathrm{w} / \mathrm{v}$ TA decreases phosphorylation of S6K1 on T389 and STAT3 on Y705, which are sites required for their kinase and transcriptional activities, respectively (Figure 2E). TA reduced CDCP1 cleavage in a concentration-dependent and statistically significant manner (Figure 2E). TA also decreased MYC expression levels, but this trend did not reach statistical significance.

\section{TA Inhibits Protein Synthesis and Reduces Histone Acetylation}

Since TA and protein synthesis inhibition by CHX both decreased STAT3 tyrosine phosphorylation (Figure 2C) and TA mimics Lys and Arg, we hypothesized that TA may inhibit protein synthesis. TA inhibited protein synthesis in a concentration-dependent manner, with $2 \%$ TA reducing protein synthesis by $60 \%$ (Figure 3A). DDAs also inhibit protein synthesis (Ferreira et al., 2017; Wang et al., 2019a; Wang et al., 2019b). Therefore, we examined if combining low concentrations of the DDA tcyDTDO and TA would suppress protein synthesis in an additive manner. Treatment with $1.25 \mu \mathrm{M}$ tcyDTDO inhibited protein synthesis by $57 \%$ and addition of increasing concentrations of TA further reduced protein synthesis (Figure 3B). Similarly, combining concentrations of TA and tcyDTDO that have little effect on cancer cell viability alone resulted in larger reductions in viability (Figure 3C).

Suppression of histone acetylation by the p300/CBP enzymes is an emerging strategy for cancer therapy (Yang et al., 2013; Gu et al., 2016; Lasko et al., 2017; Wang et al., 2017; van Gils et al., 2021). We hypothesized that TA may alter Lys acetylation through competitive inhibition of Lys acetyltransferases and next examined if TA reduces acetylation of proteins on Lys. TA at 0.5 or $1 \%$ partially blocked protein Lys acetylation of a prominent $\sim 20 \mathrm{kDa}$ band as detected with an acetyl-Lys antibody (Figure 3D, arrow). This band is likely acetylated histones, which are the most abundant acetylated cellular proteins in this molecular size range (Hansen et al., 2019). TcyDTDO also reduced acetylation of this band, and acetylation was strongly increased by treatment of the cells with the histone deacetylase inhibitor Vorinostat/SAHA. We next examined if TA could overcome the effects of SAHA. TA treatment reduced Lys acetylation, but TA did not override the increased acetylation induced by SAHA co-treatment (Figure 3E). In contrast, treatment with the DDA dMtcyDTDO (Law et al., 2021) decreased baseline Lys acetylation and blocked the SAHAdriven increase in acetylation. The p300 protein is a major cellular histone acetyltransferase (HAT). We next performed HAT enzyme assays to determine if TA or tcyDTDO directly inhibit p300 activity. TA (2\%) did not affect p300 acetylation of Histone 3 in vitro (Figure 3F). TcyDTDO also did not directly inhibit p300 activity. TA is partly metabolized in the body by acetylation $(0.5 \%$ of oral dose; http://www.accessdata.fda.gov/ drugsatfda_docs/label/2020/022430s009lbl.pdf), and perhaps also in cultured cells. Therefore, we examined if the metabolite $N$-acetyl-TA (NacTA) alters p300 activity. NacTA partially 


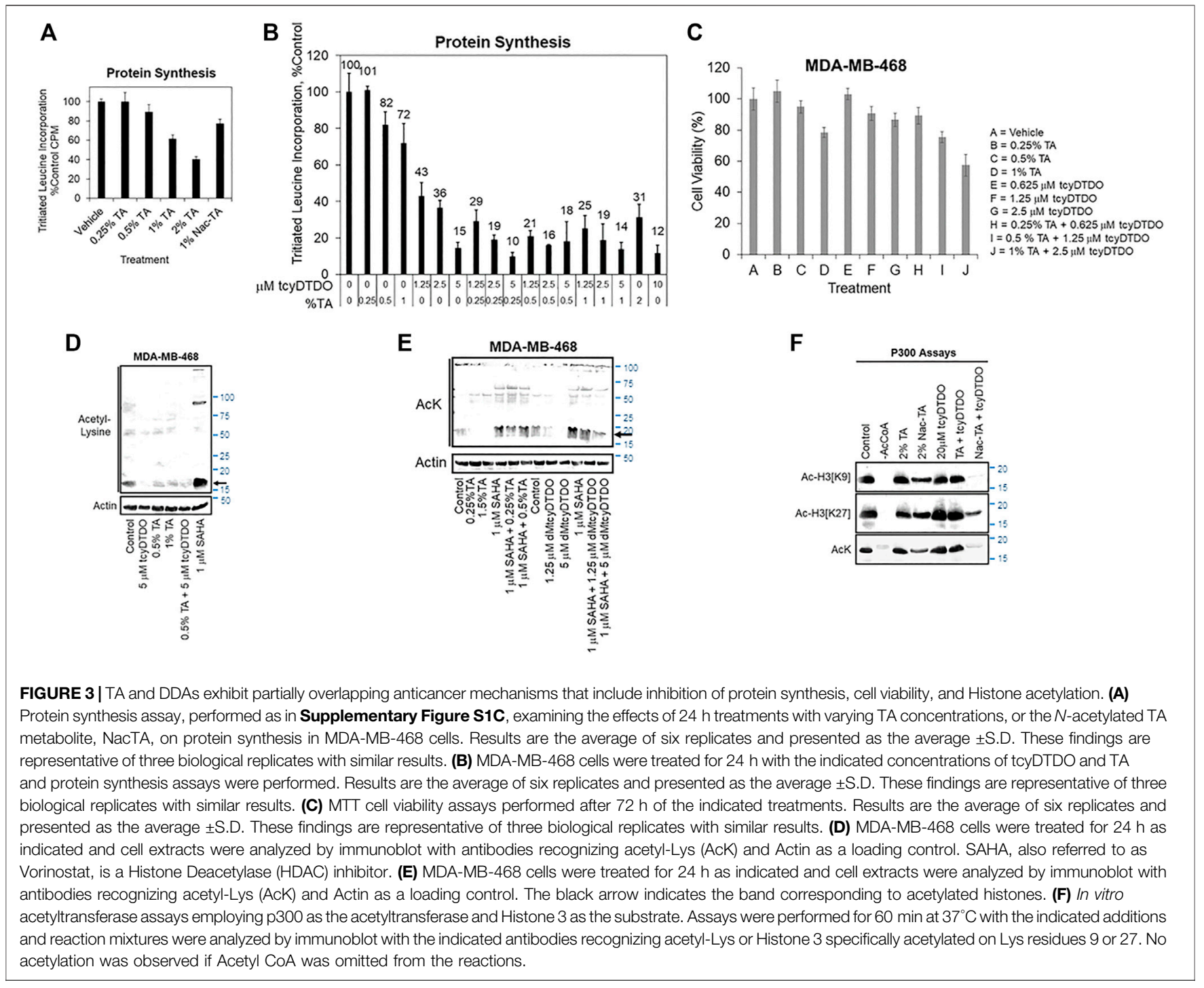

inhibited p300 HAT activity and interestingly, combining NacTA and tcyDTDO strongly inhibited overall p300 activity (AcK), as well as acetylation of Histone $\mathrm{H} 3$ on Lys residues 9 and 27. Further studies are required to determine if TA, NacTA, or DDAs reduce cellular protein acetylation through effects on p300 or other HAT enzymes. However, the results in Figures 3D-F suggest that TA and/or its metabolites and DDAs may mediate their effects in part by altering protein acetylation.

\section{Efficacy of TA/DDA Mono- and Combination Anti-Cancer Therapy}

The findings presented in Figures 1-3 indicated that TA suppressed the growth of tumors derived from 012/LVM2/ LR10 cells in a 12-day study, and cell culture studies showed that TA may suppress cancer cell viability through multiple mechanisms. The results further suggest that TA biochemical mechanisms of anticancer action partially overlap with those of
DDAs. Therefore, we examined the anticancer efficacy of $375 \mathrm{mg} / \mathrm{kg}$ TA, $10 \mathrm{mg} / \mathrm{kg}$ of the DDA dMtcyDTDO, or TA + dMtcyDTDO administered once daily by oral gavage in longerterm studies. Tumors were initiated by orthotopic injections of $10^{6}$ 012/LVM2/LR10 cells and treatment was initiated when tumors were detectable by palpation. By 20 days of treatment, tumors in vehicle-treated mice averaged over $200 \mathrm{~mm}^{3}$, while tumors in drug-treated animals were less than $50 \mathrm{~mm}^{3}$ (Figure 4A). Immunoblot analysis of tumor extracts from each group showed that TA reduced S6K1 phosphorylation on $\mathrm{Thr}^{389}$, which is required for its kinase activity (Dennis et al., 1998; McMahon et al., 2002), to a greater extent on average than the other treatments (Figure 4B). Quantification of the results in Figure 4B indicated that TA suppressed $S 6 \mathrm{~K} 1$ phosphorylation in a statistically significant manner (Figure 4C). Rapamycin analogs ("rapalogs") are in clinical use against human cancer and act in part by inhibiting S6K (Ferrari et al., 1993; Meng and Zheng 2015), and S6K inhibitors are under development as cancer 

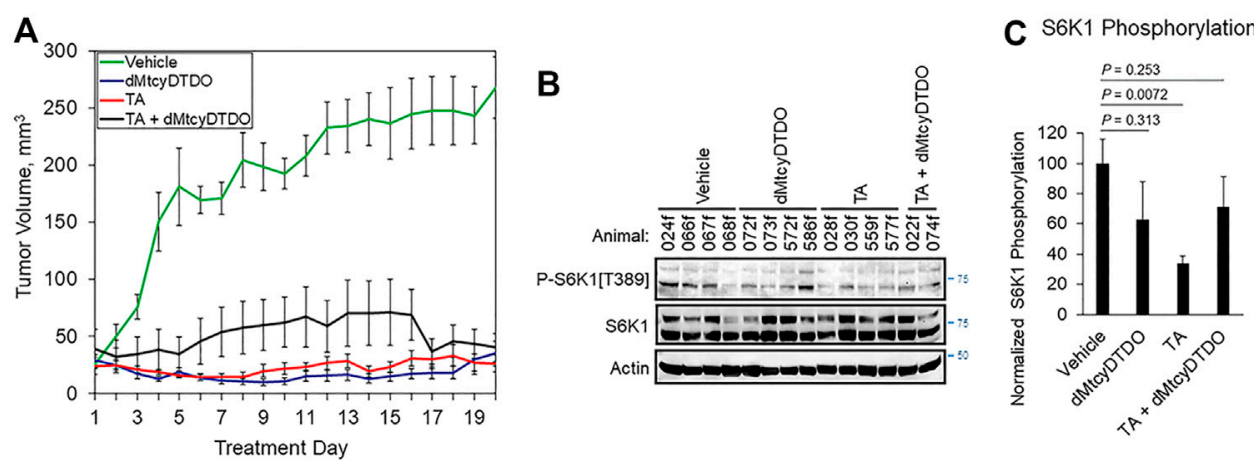

FIGURE 4 | TA blockade of breast tumor growth is associated with reduced S6K1 phosphorylation. (A) Growth curves of 012/LVM2/LR10 tumors treated once daily by oral gavage with vehicle (peanut oil), $10 \mathrm{mg} / \mathrm{kg}$ dMtcyDTDO, $375 \mathrm{mg} / \mathrm{kg}$ TA or combined treatment with the $10 \mathrm{mg} / \mathrm{kg}$ dMtcyDTDO and $375 \mathrm{mg} / \mathrm{kg}$ TA. Results are the average obtained from 10 animals in each treatment group and presented as the average \pm S.D. (B) Immunoblot analysis of tumor extracts with the indicated antibodies. (C) Plot of S6K1 phosphorylation normalized to S6K1 protein levels. Results represent the average of four samples from each treatment group. Error bars represent S.E.M. Pairwise statistical comparisons between the vehicle and drug treatment groups were made using unpaired Student's $t$-tests.

therapeutics (Pearce et al., 2010; Nam et al., 2019), consistent with the well-established role of $\mathrm{S} 6 \mathrm{~K}$ activation in the molecular pathogenesis of multiple cancers.

We previously observed that treatment with the DDA tcyDTDO caused widespread apoptosis of cancer cells in primary tumors and metastases without inducing apoptosis in adjacent normal tissues, resulting in substantial regions of dead tumor tissue (Wang et al., 2019b). This indicates that calculating tumor volumes without taking into account viability of the cancer cells may underestimate the efficacy of anticancer regimens. Further, sampling portions of such heterogeneous tumors may introduce errors into downstream proteomic or transcriptomic analyses. Therefore, we examined the morphology of Hematoxylin and Eosin (H\&E)-stained tumors from each of the four treatment groups. Two representative tumors from vehicle-treated mice (Figure 5A) exhibited predominantly viable tumor tissue (T), with small regions of dead cancer cells $(\mathrm{N})$. Higher magnification images showed mitotic figures, demonstrating cancer cell proliferation in the vehicle-treated tumors (yellow arrows). Representative tumors from dMtcyDTDO-treated animals in contrast, exhibited predominantly dead tumor tissue $(\mathrm{N})$, with small areas of apparently viable tumor cells ( $\mathrm{T}$ ) (Figure 5B). Closer inspection of the boundary between the dead and viable cancer cells showed tumor cells undergoing nuclear condensation and fragmentation (red arrows), consistent with apoptosis. Interestingly, tumors from TA-treated animals exhibited somewhat similar morphology to the tumors from dMtcyDTDO-treated animals with large regions of dead tumor tissue and tumor cells exhibiting nuclear condensation and fragmentation (red arrows, Figure 5C). Tumors from mice treated with TA + dMtcyDTDO (Figure 5D) exhibited similar morphology to the tumors from mice treated with TA or dMtcyDTDO with large regions of dead tumor tissue, tumor cells exhibiting nuclear condensation and fragmentation, and a lack of mitotic figures. A few previous studies have noted TA anticancer activity in xenograft models (Astedt and Trope 1980; Iwakawa and Tanaka 1982; Ogawa et al., 1982), and in a case report (Astedt et al., 1977), against several solid tumor types, including breast cancer. In these reports, TA anticancer activity was attributed to its antifibrinolytic actions. Our results demonstrate TA efficacy against breast tumors in animal models and identify several novel TA-induced biochemical responses that may contribute to TA anticancer activity.

\section{TA Suppression of Arg and Lys Absorption by Cancer Cells}

As mentioned above, S6K1 activation is sensitive to the levels of amino acids, as is MYC expression and the initiation of protein synthesis. Given the similarity of TA to Lys and Arg, we hypothesized that TA may compete with Lys or Arg for uptake by Cationic Amino acid Transporter (CATs). If correct, this hypothesis may also explain how TA enters cells since TA contains charged carboxyl and amino groups and is thus unlikely to traverse the plasma membrane unaided. The structure of a bacterial homolog of the mammalian CAT-family proteins (CATh) has been obtained with Arg bound (Jungnickel et al., 2018). We deleted Arg from this structure to perform in silico molecular docking to determine if TA is predicted to bind to this pocket, and if so, how its predicted binding energy compares with that of Arg or Lys. Figure 6A, upper-left and upper-middle shows a model of how TA might bind to CATh as viewed in the plane of the plasma membrane, or looking down into the transporter pore. The DOCK 6.7 program estimated Arg to have the highest binding energy for the CATh pocket, followed by TA, and Lys. It must be noted that if CATh bound to Lys or TA had served as the original model rather than CATh bound to Arg the results may have differed. However, the results obtained suggest that TA might bind to CATh with an affinity that is similar in magnitude with that of Arg and Lys. We next examined if TA suppresses the uptake of radiolabeled Arg or Lys by breast cancer cells. TA reduced the absorption of ${ }^{3} \mathrm{H}-\mathrm{Arg}$ by MDA-MB-468 cells in a concentration-dependent manner (Figure 6B). Similarly, TA decreased ${ }^{14} \mathrm{C}$-Lys uptake by MDA-MB-468 cells in a concentration-dependent manner (Figure 6C). These results suggest that TA may reduce cancer cell viability in part by inhibiting import of Lys and Arg through competition for 

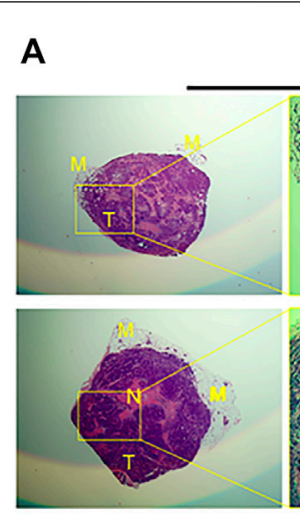

c
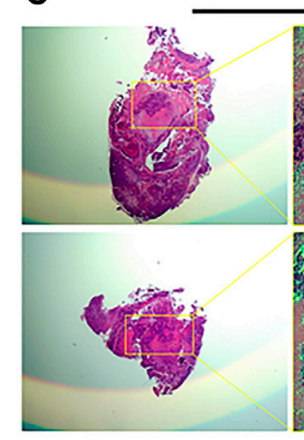

Vehicle

Magnification
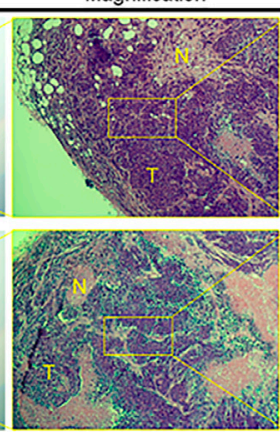

IA

Magnification
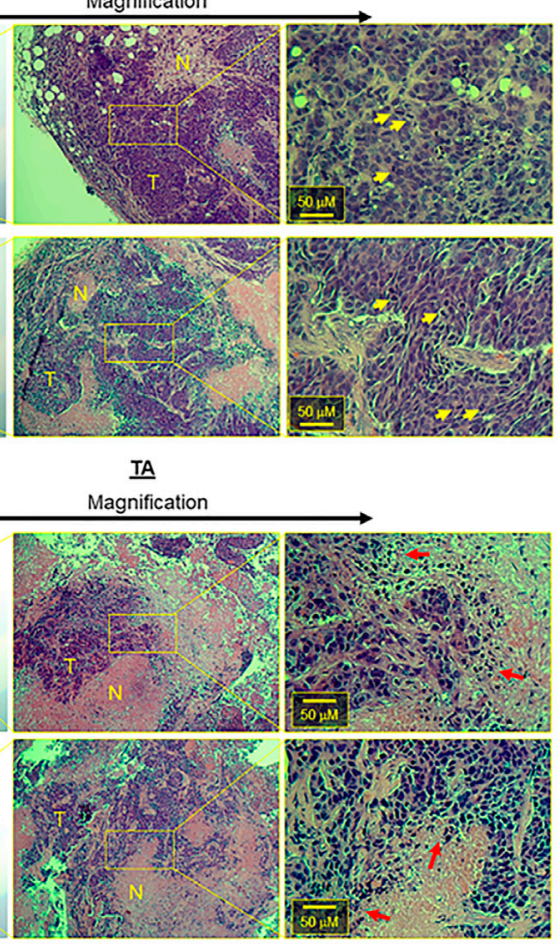

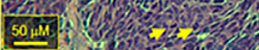

B

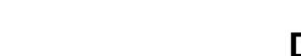

D
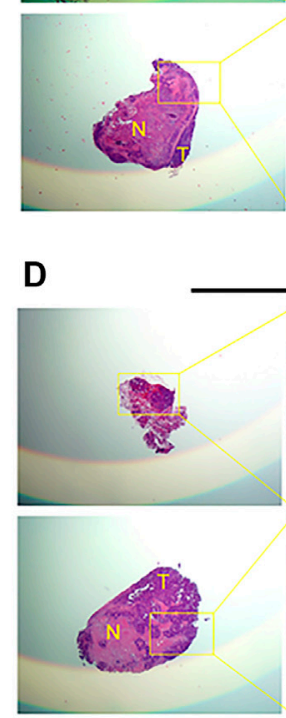
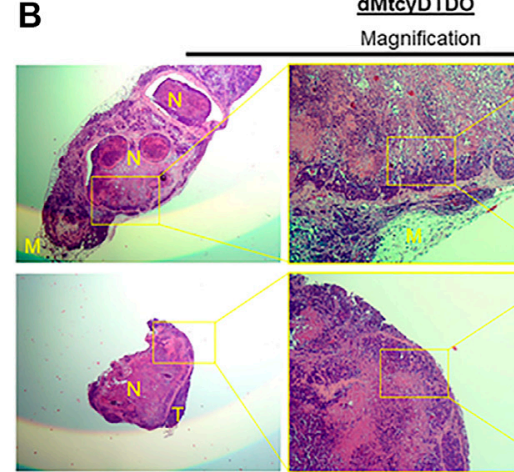

TA + dMtcyDTDO

Magnification

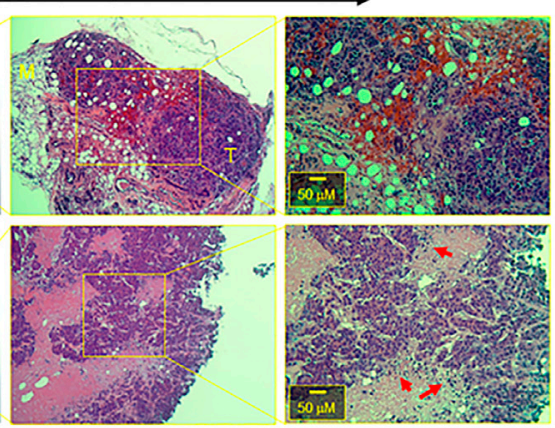

FIGURE 5 | TA and dMtcyDTDO cause tumor cell death in animal models. At endpoint, two tumors from the (A) Vehicle, (B) dMtcyDTDO, (C) TA, and (D) TA + dMtcyDTDO treatment groups were paraffin-embedded, sectioned and stained with hematoxylin and eosin (H\&E). Each section is shown at three different magnifications with scale bars on the highest magnification images. T refers to viable tumor tissue, N, necrotic/dead tissue, and M, mammary tissue. Yellow arrows denote cells undergoing mitosis and red arrows indicate cells undergoing nuclear condensation and fragmentation, indicative of cell death.

CATs or other amino acid transporters, and that TA might enter cancer cells through these same transporters.

\section{DISCUSSION}

Previous work suggested that TA might exhibit anticancer activity by inhibiting Plasmin activity and by preventing Plasminogen conversion to Plasmin (O'Grady et al., 1981; Tanaka et al., 1982; Stonelake et al., 1997; Dunbar et al., 2000; Suojanen et al., 2009). The results presented here indicate that TA blocks cleavage of the Plasmin substrate CDCP1. Some reports indicate that the cleaved form of CDCP1 exhibits enhanced oncogenic functions and a different spectrum of protein-protein interactions than the full-length protein (Casar et al., 2014; Law et al., 2016; Wright et al., 2016). Suppression of CDCP1 cleavage by TA may be preferable to that induced by TGF $\beta$ and glucocorticoids since these agents block Plasminogen activation by upregulating Plasminogen Activator Inhibitor-1 (PAI-1) and activate transcriptional programs that may not be beneficial in the cancer setting. However, blockade of Plasminogen activation and cleavage of CDCP1 and other Plasmin substrates represents only one of the biochemical actions of TA that could contribute to its anticancer activity.

The MYC and STAT3 oncoproteins are widely overexpressed or activated across human cancers and the mTORC1/S6K1 pathway is frequently stimulated in malignancies. Of interest is the observation that MYC transformed MCF10A mammary epithelial cells are more sensitive to TA-mediated reduction in cell viability than vector control cells. This may be due to MYCmediated monopolization of the protein translation machinery and regulation of the translation factors eIF4E, eIF4A, and eIF4G (Ruggero 2009; Flynn and Hogarty 2018) and could explain in part how TA suppresses breast tumor growth in animal models without evidence of toxicity. Given these observations, more work is warranted to elucidate the biochemical mechanisms by which TA suppresses MYC expression, and STAT3 and S6K1 phosphorylation, and reduces histone acetylation. The protein synthesis inhibitor Cycloheximide partially blocked STAT3 tyrosine phosphorylation (Figure 2C), but did not reduce MYC levels or S6K1 phosphorylation, indicating that the latter two TA effects are independent of protein synthesis inhibition.

TA inhibition of protein synthesis is of particular interest because Asparaginase, which depletes asparagine and glutamine, is in clinical use against leukemia (reviewed in Nikolaev 1969) and functions in part by suppressing protein synthesis (Ellem et al., 1970; Kessel and Bosmann 1970; Benvenisty 1972) and by inhibiting mTORC1/S6K1 signaling (Nikonorova et al., 2018). Asparaginase resistance remains a significant clinical problem (Apfel et al., 2021) and as a protein drug, Asparaginase suffers from issues associated with instability and rapid clearance (Varshosaz and Anvari 2018) and allergenicity (Belen et al., 
A
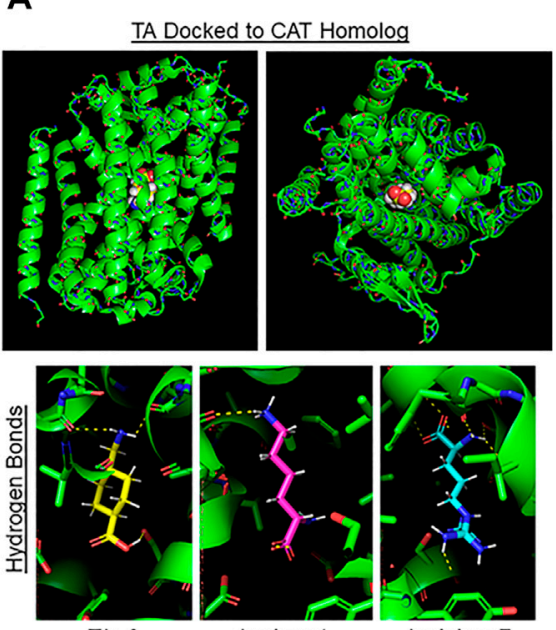

TA: 3

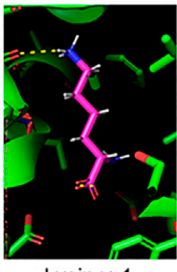

Lysine: 1

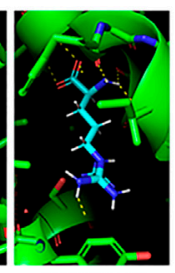

Arginine: 7
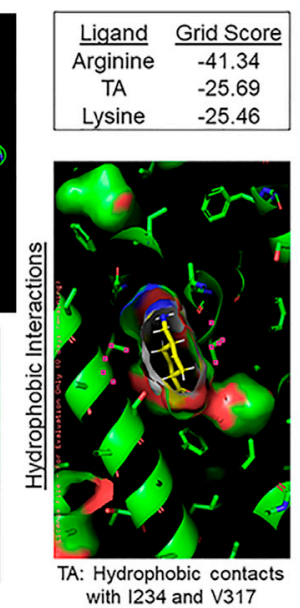

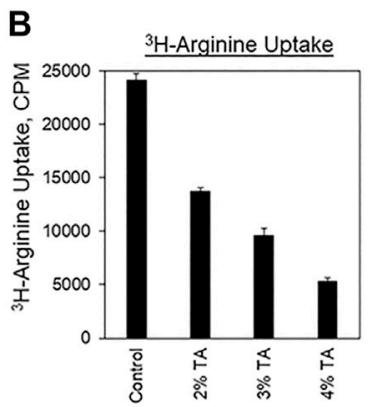

C
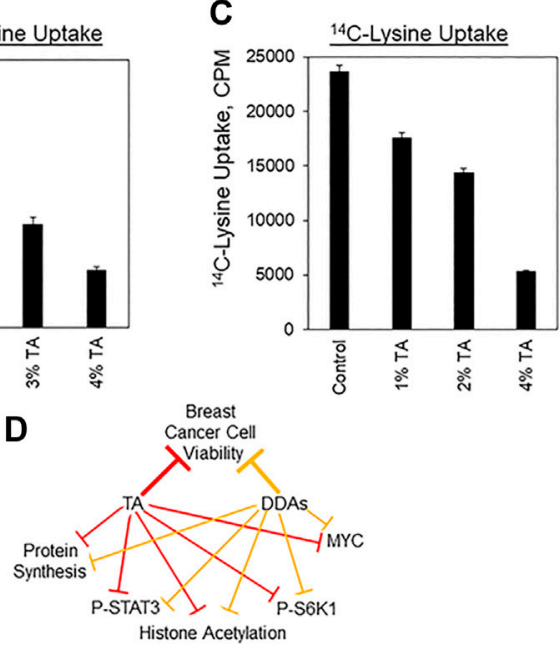

FIGURE 6 | TA inhibits Lys and Arg absorption by cancer cells. (A) Molecular docking of TA into the Arg binding pocket of the bacterial homolog of the Cationic Amino acid Transporters (CATh). Upper-left: Image of TA docked to CATh in the plane of the plasma membrane. Upper-middle: View of TA docked into CATh orthogonal to the membrane. Upper-right: Binding energy scores for Arg, TA, or Lys binding to the Arg binding pocket of CATh estimated by DOCK 6.7. Lower-left: Hydrogen bonds between CATh and TA, Lys, or Arg predicted by PyMol. Lower-right: Hydrophobic contacts between I234 and V317 of CATh with the cyclohexane ring of TA predicted by PyMol. (B) ${ }^{3} \mathrm{H}$-Arg uptake by MDA-MB-468 cells during a $2 \mathrm{~h}$ labeling pulse in the presence of the indicated concentrations of TA. Results are the average of six replicates and presented as the average \pm S.D. These findings are representative of three biological replicates with similar results. (C) ${ }^{14} \mathrm{C}$-Lys uptake by MDA-MB-468 cells during a $2 \mathrm{~h}$ labeling pulse in the presence of the indicated concentrations of TA. Results are the average of six replicates and presented as the average \pm S.D. These findings are representative of three biological replicates with similar results. (D) Model displaying the overlapping biochemical mechanisms by which TA and DDAs may suppress breast tumor growth.

2019). Thus, a small molecule drug such as TA or a TA analog may be useful against Asparaginase-resistant malignancies or in patients with Asparaginase allergies. Examining TA effects on Lys/Arg absorption by cancer cells showed inhibition of uptake of both amino acids. Depletion of cellular Lys/Arg could explain TA-induced suppression of protein synthesis and reduced S6K1 phosphorylation (Drummond et al., 2008). Since solid tumors are expected to be nutrient-deprived in their avascular centers, the consequences of TA suppression of Lys/ Arg uptake may be amplified in the tumor microenvironment. Amino acid levels also regulate the process of autophagy, which may mediate cell death depending on the circumstances. Future studies should examine if TA treatment stimulates autophagy, and if autophagy contributes to the anticancer actions of TA.

Results posted in a preprint suggest that DDAs may suppress tumor growth by inhibiting a subset of Protein Disulfide Isomerases (PDIs) (Law et al., 2021). Interestingly, DDAs exhibit some activities that overlap with those of TA, including decreased MYC expression, sensitivity enhancement by MYC overexpression, lowering of STAT3 tyrosine phosphorylation and S6K1 phosphorylation on $\mathrm{Thr}^{389}$ and Ser ${ }^{411}$, inhibition of protein synthesis, and reduced histone acetylation. Figure $6 \mathrm{D}$ summarizes the common biochemical responses to TA and DDAs that are hypothesized to mediate in part, the anticancer activity of these compounds. The results in Figure 4 examining TA/DDA mono- and combination regimens against breast tumors indicate that TA suppresses S6K1 phosphorylation on $\mathrm{Thr}^{389}$ in tumors in vivo.

TA exhibits anticancer activity in mice at a dosage of $375 \mathrm{mg} / \mathrm{kg}$ (Figures 1F, 4A). Future studies are required to determine whether similar TA anticancer activity is observed at lower dosages.
Clinically, TA has been used at dosages of $20 \mathrm{mg} / \mathrm{kg}$ to suppress postoperative bleeding (Andersson et al., 1968). The most common intravenous dosages used clinically are $10-20 \mathrm{mg} / \mathrm{kg}$, given every 6-8 h, or simply before and after surgery (Lecker et al., 2012). Administration of $240 \mathrm{mg} / \mathrm{h}$ TA was used to prevent life-threatening bleeding in advanced cancer patients (Atreya 2021). However, dosages as high as $100 \mathrm{mg} / \mathrm{kg}$ followed by $10 \mathrm{mg} / \mathrm{kg} /$ hour were given previously, until it was found that total doses of $80-100 \mathrm{mg} / \mathrm{kg}$ led to a small increase in post-operative seizures. Seizures are an important side effect of TA when used at high dosages (Mohseni et al., 2009; Kalavrouziotis et al., 2012). This is thought to result primarily from TA induction of neuronal hyperexcitability due to antagonism of glycine binding to glycine receptors, which hyperpolarize neurons (Lecker et al., 2012). Importantly, this neuronal hyperexcitability may be overcome using the common surgical anesthetics isoflurane and propofol (Lecker et al., 2012). In addition, seizures have been observed almost only following cardiac surgery, and this effect may not be applicable or as significant in systemic treatment of non-surgical cancer patients.

TA side effects may also be avoided by using it against skin cancers via topical administration or against other surfaceaccessible malignancies such as superficial bladder cancers (Javadpour 1989) or lung tumors (Moghissi et al., 2004; Jang et al., 2006). Although a $1 \%(\mathrm{w} / \mathrm{v}) \mathrm{TA}$ concentration is $64 \mathrm{mM}$, this concentration is in line with established topical or intradermal concentrations administered for bleeding reduction $(0.7 \%$, (Ker et al., 2013)), melasma (3\%, (Ebrahimi and Naeini 2014)), or rosacea (5-10\%, (Jakhar et al., 2020; Daadaa et al., 2021)). In addition, it has been well established that topically administered 
TA has less than $10 \%$ of the systemic impact of a similar dose delivered intravenously (Ker et al., 2013; Ausen et al., 2019). Given the small volumes that are likely to be administered topically, the risk of seizure would not appear to be an issue.

It should be noted that while TA is not currently approved for use as an anticancer agent, TA is employed with increasing frequency in various aspects of clinical cancer management. TA is often used to limit bleeding during surgical tumor resections (Wu et al., 2006; Longo et al., 2018; Jaffer et al., 2021). TA treatment is associated with a reduction in the number of malignant cells and decreased generation of ascites fluid in patients with disseminated ovarian cancer (Soma et al., 1980; Kikuchi et al., 1986). In the treatment of node-positive, operable breast cancer, the axillary lymph nodes are dissected out, and this is associated with excessive axillary drainage and risk of infection. TA treatment reduces axillary drainage and decreases the rate of complications in these patients (Oertli et al., 1994; Lohani et al., 2020; Lohani et al., 2021). It will be important to determine in these clinical scenarios where TA is used to control treatment-associated morbidities, if TA also contributes to improved patient outcome through direct actions against any remaining cancer cells. If so, then in cancers such as Triple-Negative Breast Cancer (TNBC), which exhibit high rates of post-surgical recurrence (Pilewskie et al., 2014; Radosa et al., 2017), TA treatment before or after tumor resection might reduce the rate of cancer recurrence.

The beneficial actions of TA in inhibiting Plasmin activation and activity in the cancer setting are well appreciated, but to our knowledge, the present study is the first to survey the effects of TA on an array of other signaling pathways and proteins with roles in tumor growth and progression. The different pharmacological mechanisms of action exhibited by TA may be explained by the ability of TA to antagonize Lys and Gly binding sites, and perhaps also Arg and His binding sites. Additional work is needed to elucidate how TA mediates its Plasmin-independent signaling effects. Additionally, TA is anti-inflammatory and modulates the innate immune system (Draxler et al., 2019). This study by Draxler et al. was performed alongside the major prospective safety study of TA, ATACAS, where they found that use of TA did not cause an increase in thromboembolic events in the only prospective study with sufficient power to prove this point. The Draxler adjunctive study found that the patients who received TA had significantly fewer post-operative infections, despite the fact that every patient received prophylactic antibiotics. Draxer et al. also administered a standard dose of TA to healthy volunteers. In both the healthy volunteers and the surgical patients they found that TA upregulated multiple immune-enhancing markers and downregulated multiple immunosuppressive markers.

We hypothesize that the multiple anticancer activities of TA may delay or block the acquisition of tumor resistance, and this might be further enhanced by combining TA with other classes of anticancer agents and/or therapies. It will also be important in future studies to determine if TA metabolites such as NacTA play significant roles in the responses of cancer cells to TA. The observation that TA elicits multiple biochemical responses that are expected to block tumor growth and progression suggests that it may be possible to design new TA analogs that more potently or selectively trigger individual downstream TA anticancer actions.
Specifically, TA analogs may be designed that do not antagonize the glycine receptor and cause seizures, and are more potent inhibitors of Arg and Lys transporters.

\section{DATA AVAILABILITY STATEMENT}

The original contributions presented in the study are included in the article/Supplementary Material, further inquiries can be directed to the corresponding author.

\section{ETHICS STATEMENT}

The animal study was reviewed and approved by the University of Florida Institutional Animal Care and Use Committee; Study \#201908029.

\section{AUTHOR CONTRIBUTIONS}

Conceptualized Studies: ML, AG, MW, SJ, RC, and BL. Performed Experiments: ML, BD, AG, MW, SJ, and BL. Synthesized Compounds: EY, AG, and ZD. Analyzed Results: ML, BD, MW, CH, and BL. Provided Critical Reagents: AG, OG, $\mathrm{CH}$, and RC. Participated in Manuscript Writing/Editing: ML, BD, AG, MW, OG, CH, SJ, RC, and BL. Obtained Funding for the Study: BL, RC, $\mathrm{CH}$, and OG.

\section{FUNDING}

This study was funded in part by NIH/NCI grant R21CA252400 and Tranexamic Technologies, LLC (BL and RC). Work performed by $\mathrm{CH}$ was supported in part by NIH/NINDS grant R01NS102624. OG was supported by R01DK121831. The work was funded by Tranexamic Technologies, Inc., which could benefit from the research findings. The mass spectrometric data were obtained by the UF Department of Chemistry Mass Spectrometry Research and Education Center supported, in part, by the National Institutes of Health (NIH S10 OD021758-01A1).

\section{ACKNOWLEDGMENTS}

We thank Drs. Daiqing Liao (UF) and Aaron Waddell (UF) for advice on p300 acetyltransferase assays and Dr. Michael Kilberg (UF) for providing the MOLT4s cell line. We are grateful to Dr. W. Douglas Cress (Moffitt Cancer Center) for providing the WM793 cell line.

\section{SUPPLEMENTARY MATERIAL}

The Supplementary Material for this article can be found online at: https://www.frontiersin.org/articles/10.3389/fphar.2021.792600/ full\#supplementary-material 


\section{REFERENCES}

Allen, W. J., Balius, T. E., Mukherjee, S., Brozell, S. R., Moustakas, D. T., Lang, P. T., et al. (2015). DOCK 6: Impact of New Features and Current Docking Performance. J. Comput. Chem. 36, 1132-1156. doi:10.1002/jcc.23905

Andersson, L., Nilsoon, I. M., Colleen, S., Granstrand, B., and Melander, B. (1968). Role of Urokinase and Tissue Activator in Sustaining Bleeding and the Management Thereof with EACA and AMCA. Ann. N. Y Acad. Sci. 146, 642-658. doi:10.1111/j.1749-6632.1968.tb20322.x

Apfel, V., Begue, D., Cordo, V., Holzer, L., Martinuzzi, L., Buhles, A., et al. (2021). Therapeutic Assessment of Targeting ASNS Combined with L-Asparaginase Treatment in Solid Tumors and Investigation of Resistance Mechanisms. ACS Pharmacol. Transl Sci. Feb 12 (4), 327-337. doi:10.1021/acsptsci.0c00196

Astedt, B., Mattsson, W., and Tropé, C. (1977). Treatment of Advanced Breast Cancer with Chemotherapeutics and Inhibition of Coagulation and Fibrinolysis. Acta Med. Scand. 201, 491-493. doi:10.1111/j.09546820.1977.tb15735.x

Astedt, B., and Tropé, C. (1980). Effect of Tranexamic Acid on Progress of Experimental Tumours and on DNA-Synthesis. Experientia 36, 679-680. doi:10.1007/BF01970136

Atreya, S. (2021). High-dose Continuous Infusion of Tranexamic Acid for Controlling Life-Threatening Bleed in Advanced Cancer Patients. Indian J. Palliat. Care 27, 172-175. doi:10.4103/IJPC.IJPC_48_20

Ausen, K., Pleym, H., Liu, J., Hegstad, S., Nordgård, H. B., Pavlovic, I., et al. (2019). Serum Concentrations and Pharmacokinetics of Tranexamic Acid after Two Means of Topical Administration in Massive Weight Loss Skin-Reducing Surgery. Plast. Reconstr. Surg. 143, 1169e-1178e. doi:10.1097/ PRS.0000000000005620

Belén, L. H., Lissabet, J. B., de Oliveira Rangel-Yagui, C., Effer, B., Monteiro, G., Pessoa, A., et al. (2019). A Structural In Silico Analysis of the Immunogenicity of L-Asparaginase from Escherichia coli and Erwinia Carotovora. Biologicals 59, 47-55. doi:10.1016/j.biologicals.2019.03.003

Benvenisty, D. S. (1972). Inhibition of Synthesis of Protein and Nucleic Acid in Mouse and Human Leukemia Cells by L-Asparaginase In Vitro. Harefuah 82, 68-70.

Besse, L., Besse, A., Mendez-Lopez, M., Vasickova, K., Sedlackova, M., Vanhara, P., et al. (2019). A Metabolic Switch in Proteasome Inhibitor-Resistant Multiple Myeloma Ensures Higher Mitochondrial Metabolism, Protein Folding and Sphingomyelin Synthesis. Haematologica 104, e415-e419. doi:10.3324/ haematol.2018.207704

Blee, T. K., Gray, N. K., and Brook, M. (2015). Modulation of the Cytoplasmic Functions of Mammalian post-transcriptional Regulatory Proteins by Methylation and Acetylation: a Key Layer of Regulation Waiting to Be Uncovered. Biochem. Soc. Trans. 43, 1285-1295. doi:10.1042/BST20150172

Casar, B., Rimann, I., Kato, H., Shattil, S. J., Quigley, J. P., and Deryugina, E. I. (2014). In Vivo cleaved CDCP1 Promotes Early Tumor Dissemination via Complexing with Activated $\beta 1$ Integrin and Induction of FAK/PI3K/Akt Motility Signaling. Oncogene 33, 255-268. doi:10.1038/onc.2012.547

Corsino, P., Horenstein, N., Ostrov, D., Rowe, T., Law, M., Barrett, A., et al. (2009). A Novel Class of Cyclin-dependent Kinase Inhibitors Identified by Molecular Docking Act through a Unique Mechanism. J. Biol. Chem. 284, 29945-29955. doi:10.1074/jbc.M109.055251

Daadaa, N., Litaiem, N., Karray, M., Bacha, T., Jones, M., Belajouza Noueiri, C., et al. (2021). Intradermal Tranexamic Acid Microinjections: a Novel Treatment Option for Erythematotelangiectatic Rosacea. J. Cosmet. Dermatol. 20, 3324-3329. doi:10.1111/jocd.14209

Dennis, P. B., Pullen, N., Pearson, R. B., Kozma, S. C., and Thomas, G. (1998). Phosphorylation Sites in the Autoinhibitory Domain Participate in P70(s6k) Activation Loop Phosphorylation. J. Biol. Chem. 273, 14845-14852. doi:10.1074/jbc.273.24.14845

Draxler, D. F., Awad, M. M., Hanafi, G., Daglas, M., Ho, H., Keragala, C. B., et al. (2019). Tranexamic Acid Influences the Immune Response, but Not Bacterial Clearance in a Model of post-traumatic Brain Injury Pneumonia. J. Neurotrauma. May 29, 119. doi:10.1089/neu.2018.6030

Drummond, M. J., Bell, J. A., Fujita, S., Dreyer, H. C., Glynn, E. L., Volpi, E., et al. (2008). Amino Acids Are Necessary for the Insulin-Induced Activation of mTOR/S6K1 Signaling and Protein Synthesis in Healthy and Insulin Resistant
Human Skeletal Muscle. Clin. Nutr. 27, 447-456. doi:10.1016/ j.clnu.2008.01.012

Dunbar, S. D., Ornstein, D. L., and Zacharski, L. R. (2000). Cancer Treatment with Inhibitors of Urokinase-type Plasminogen Activator and Plasmin. Expert Opin. Investig. Drugs 9, 2085-2092. doi:10.1517/13543784.9.9.2085

Ebrahimi, B., and Naeini, F. F. (2014). Topical Tranexamic Acid as a Promising Treatment for Melasma. J. Res. Med. Sci. 19, 753-757.

Ellem, K. A., Fabrizio, A. M., and Jackson, L. (1970). The Dependence of DNA and RNA Synthesis on Protein Synthesis in Asparaginase-Treated Lymphoma Cells. Cancer Res. 30, 515-527.

Ferrari, S., Pearson, R. B., Siegmann, M., Kozma, S. C., and Thomas, G. (1993). The Immunosuppressant Rapamycin Induces Inactivation of P70s6k through Dephosphorylation of a Novel Set of Sites. J. Biol. Chem. 268, 16091-16094. doi:10.1016/s0021-9258(19)85389-9

Ferreira, R. B., Law, M. E., Jahn, S. C., Davis, B. J., Heldermon, C. D., Reinhard, M., et al. (2015). Novel Agents that Downregulate EGFR, HER2, and HER3 in Parallel. Oncotarget 6, 10445-10459. doi:10.18632/oncotarget.3398

Ferreira, R. B., Wang, M., Law, M. E., Davis, B. J., Bartley, A. N., Higgins, P. J., et al. (2017). Disulfide Bond Disrupting Agents Activate the Unfolded Protein Response in EGFR- and HER2-Positive Breast Tumor Cells. Oncotarget 8, 28971-28989. doi:10.18632/oncotarget.15952

Flynn, A. T., and Hogarty, M. D. (2018). Myc, Oncogenic Protein Translation, and the Role of Polyamines. Med. Sci. (Basel) 6, 41. doi:10.3390/ medsci6020041

Gu, M. L., Wang, Y. M., Zhou, X. X., Yao, H. P., Zheng, S., Xiang, Z., et al. (2016). An Inhibitor of the Acetyltransferases CBP/p300 Exerts Antineoplastic Effects on Gastrointestinal Stromal Tumor Cells. Oncol. Rep. 36, 2763-2770. doi:10.3892/or.2016.5080

Han, J. W., Pearson, R. B., Dennis, P. B., and Thomas, G. (1995). Rapamycin, Wortmannin, and the Methylxanthine SQ20006 Inactivate P70s6k by Inducing Dephosphorylation of the Same Subset of Sites. J. Biol. Chem. 270, 21396-21403. doi:10.1074/jbc.270.36.21396

Hansen, B. K., Gupta, R., Baldus, L., Lyon, D., Narita, T., Lammers, M., et al. (2019). Analysis of Human Acetylation Stoichiometry Defines Mechanistic Constraints on Protein Regulation. Nat. Commun. 10, 1055. doi:10.1038/s41467-01909024-0

He, Y., Wortmann, A., Burke, L. J., Reid, J. C., Adams, M. N., Abdul-Jabbar, I., et al (2010). Proteolysis-induced N-Terminal Ectodomain Shedding of the Integral Membrane Glycoprotein CUB Domain-Containing Protein 1 (CDCP1) Is Accompanied by Tyrosine Phosphorylation of its C-Terminal Domain and Recruitment of Src and PKCdelta. J. Biol. Chem. 285, 26162-26173. doi:10.1074/jbc.M109.096453

Hidayat, S., Yoshino, K., Tokunaga, C., Hara, K., Matsuo, M., and Yonezawa, K. (2003). Inhibition of Amino Acid-mTOR Signaling by a Leucine Derivative Induces G1 Arrest in Jurkat Cells. Biochem. Biophys. Res. Commun. 301, 417-423. doi:10.1016/s0006-291x(02)03052-8

Hsieh, A. L., and Dang, C. V. (2016). MYC, Metabolic Synthetic Lethality, and Cancer. Recent Results Cancer Res. 207, 73-91. doi:10.1007/978-3-31942118-6 4

Iiboshi, Y., Papst, P. J., Kawasome, H., Hosoi, H., Abraham, R. T., Houghton, P. J., et al. (1999). Amino Acid-dependent Control of P70(s6k). Involvement of tRNA Aminoacylation in the Regulation. J. Biol. Chem. 274, 1092-1099. doi:10.1074/jbc.274.2.1092

Iwakawa, A., and Tanaka, K. (1982). Effect of Fibrinolysis Inhibitor and Chemotherapeutics on the Growth of Human Cancers Transplanted into Nude Mice and in Tissue Culture. Invasion Metastasis 2, 232-248.

Iwamoto, M. (1975). Plasminogen-plasmin System IX. Specific Binding of Tranexamic Acid to Plasmin. Thromb. Diath Haemorrh 33, 573-585. doi:10.1055/s-0038-1647851

Izzo, A., and Schneider, R. (2010). Chatting Histone Modifications in Mammals. Brief. Funct. Genomics 9, 429-443. doi:10.1093/bfgp/elq024

Jaffer, A. A., Karanicolas, P. J., Davis, L. E., Behman, R., Hanna, S. S., Law, C. H., et al. (2021). The Impact of Tranexamic Acid on Administration of Red Blood Cell Transfusions for Resection of Colorectal Liver Metastases. Hpb 23, 245-252. doi:10.1016/j.hpb.2020.06.004

Jakhar, D., Kaur, I., and Misri, R. (2020). Topical 10\% Tranexamic Acid for Erythematotelangiectatic Steriod Induced Rosacea. J. Am. Acad. Dermatol. [Online ahead of print]. doi:10.1016/j.jaad.2019.12.067 
Jang, T. W., Kim, H. K., Oak, C. H., and Jung, M. H. (2006). Photodynamic Therapy in Early Lung Cancer: a Report of Two Cases. Korean J. Intern. Med. 21, 178-182. doi:10.3904/kjim.2006.21.3.178

Javadpour, N. (1989). Photodynamic Therapy of Superficial Bladder Cancer. $M d$. Med. J. 38, 461.

Jungnickel, K. E. J., Parker, J. L., and Newstead, S. (2018). Structural Basis for Amino Acid Transport by the CAT Family of SLC7 Transporters. Nat. Commun. 9, 550. doi:10.1038/s41467-018-03066-6

Kalavrouziotis, D., Voisine, P., Mohammadi, S., Dionne, S., and Dagenais, F. (2012). High-dose Tranexamic Acid Is an Independent Predictor of Early Seizure after Cardiopulmonary Bypass. Ann. Thorac. Surg. 93, 148-154. doi:10.1016/j.athoracsur.2011.07.085

Ker, K., Beecher, D., and Roberts, I. (2013). Topical Application of Tranexamic Acid for the Reduction of Bleeding. Cochrane Database Syst. Rev., CD010562. doi:10.1002/14651858.cd010562.pub2

Kessel, D., and Bosmann, H. B. (1970). Effects of L-Asparaginase on Protein and Glycoprotein Synthesis. FEBS Lett. 10, 85-88. doi:10.1016/0014-5793(70) 80422-7

Kikuchi, Y., Kizawa, I., Oomori, K., Matsuda, M., and Kato, K. (1986). Adjuvant Effects of Tranexamic Acid to Chemotherapy in Ovarian Cancer Patients with Large Amount of Ascites. Acta Obstet. Gynecol. Scand. 65, 453-456. doi:10.3109/00016348609157383

Kusakabe, T., Yamazaki, K., Ohgiya, T., and Shibuya, K. (2010). Method for Preparing Trans-\{4-[(alkylamino) Methyl]- Cyclohexyl\}acetic Acid Ester. Available at: https://patentsgooglecom/patent/US8841478B2/en (Accessed September 17, 2021).

Laskey, R. A., Görlich, D., Madine, M. A., Makkerh, J. P., and Romanowski, P. (1996). Regulatory Roles of the Nuclear Envelope. Exp. Cel Res 229, 204. doi:10.1006/excr.1996.0361

Lasko, L. M., Jakob, C. G., Edalji, R. P., Qiu, W., Montgomery, D., Digiammarino, E. L., et al. (2017). Discovery of a Selective Catalytic P300/CBP Inhibitor that Targets Lineage-specific Tumours. Nature 550, 128-132. doi:10.1038/ nature 24028

Law, B. K., Chytil, A., Dumont, N., Hamilton, E. G., Waltner-Law, M. E., Aakre, M. E., et al. (2002). Rapamycin Potentiates Transforming Growth Factor BetaInduced Growth Arrest in Nontransformed, Oncogene-Transformed, and Human Cancer Cells. Mol. Cel Biol 22, 8184-8198. doi:10.1128/ mcb.22.23.8184-8198.2002

Law, B. K., Norgaard, P., and Moses, H. L. (2000a). Farnesyltransferase Inhibitor Induces Rapid Growth Arrest and Blocks P70s6k Activation by Multiple Stimuli. J. Biol. Chem. 275, 10796-10801. doi:10.1074/jbc.275.15.10796

Law, B. K., Waltner-Law, M. E., Entingh, A. J., Chytil, A., Aakre, M. E., Nørgaard, P., et al. (2000b). Salicylate-induced Growth Arrest Is Associated with Inhibition of P70s6k and Down-Regulation of C-Myc, Cyclin D1, Cyclin A, and Proliferating Cell Nuclear Antigen. J. Biol. Chem. 275, 38261-38267. doi:10.1074/jbc.M005545200

Law, M. E., Corsino, P. E., Jahn, S. C., Davis, B. J., Chen, S., Patel, B., et al. (2013). Glucocorticoids and Histone Deacetylase Inhibitors Cooperate to Block the Invasiveness of Basal-like Breast Cancer Cells through Novel Mechanisms. Oncogene 32, 1316-1329. doi:10.1038/onc.2012.138

Law, M. E., Ferreira, R. B., Davis, B. J., Higgins, P. J., Kim, J. S., Castellano, R. K., et al. (2016). CUB Domain-Containing Protein 1 and the Epidermal Growth Factor Receptor Cooperate to Induce Cell Detachment. Breast Cancer Res. 18, 80. doi:10.1186/s13058-016-0741-1

Law, M. E., Yaaghubi, E., Ghilardi, A. F., Davis, B. J., Ferreira, R. B., Koh, J., et al. (2021). Inhibitors of ERp44, PDIA1, and AGR2 Induce Disulfide-Mediated Oligomerization of Death Receptors 4 and 5 and Cancer Cell Death. bioRxiv, 426390. doi:10.1101/2021.01.13.426390

Lecker, I., Wang, D. S., Romaschin, A. D., Peterson, M., Mazer, C. D., and Orser, B. A. (2012). Tranexamic Acid Concentrations Associated with Human Seizures Inhibit glycine Receptors. J. Clin. Invest. 122, 4654-4666. doi:10.1172/JCI63375

Lee, H. Y., Cha, J., Kim, S. K., Park, J. H., Song, K. H., Kim, P., et al. (2019). c-MYC Drives Breast Cancer Metastasis to the Brain, but Promotes Synthetic Lethality with TRAIL. Mol. Cancer Res. 17, 544-554. doi:10.1158/1541-7786.MCR-180630

Liu, H., Ong, S. E., Badu-Nkansah, K., Schindler, J., White, F. M., and Hynes, R. O. (2011). CUB-domain-containing Protein 1 (CDCP1) Activates Src to Promote
Melanoma Metastasis. Proc. Natl. Acad. Sci. U S A. 108, 1379-1384. doi:10.1073/pnas.1017228108

Lohani, K. R., Kumar, C., Kataria, K., Srivastava, A., Ranjan, P., and Dhar, A. (2020). Role of Tranexamic Acid in Axillary Lymph Node Dissection in Breast Cancer Patients. Breast J. 26, 1316-1320. doi:10.1111/tbj.13810

Lohani, K. R., Kumar, C., Kataria, K., Srivastava, A., Ranjan, P., and Dhar, A. (2021). Role of Tranexamic Acid in Axillary Lymph Node Dissection in Breast Cancer Patients: Does it Help in Reducing Lymphedema. Breast J. 27, 502. doi:10.1111/tbj.14222

Longo, M. A., Cavalheiro, B. T., and de Oliveira Filho, G. R. (2018). Systematic Review and Meta-Analyses of Tranexamic Acid Use for Bleeding Reduction in Prostate Surgery. J. Clin. Anesth. 48, 32-38. doi:10.1016/j.jclinane.2018.04.014

McMahon, L. P., Choi, K. M., Lin, T. A., Abraham, R. T., and Lawrence, J. C., Jr (2002). The Rapamycin-Binding Domain Governs Substrate Selectivity by the Mammalian Target of Rapamycin. Mol. Cel Biol. 22, 7428-7438. doi:10.1128/ mcb.22.21.7428-7438.2002

Meng, L. H., and Zheng, X. F. (2015). Toward Rapamycin Analog (Rapalog)-based Precision Cancer Therapy. Acta Pharmacol. Sin 36, 1163-1169. doi:10.1038/ aps. 2015.68

Moghissi, K., Dixon, K., Thorpe, J. A., Oxtoby, C., and Stringer, M. R. (2004). Photodynamic Therapy (PDT) for Lung Cancer: the Yorkshire Laser Centre Experience. Photodiagnosis Photodyn Ther. 1, 253-262. doi:10.1016/S15721000(04)00047-X

Mohseni, K., Jafari, A., Nobahar, M. R., and Arami, A. (2009). Polymyoclonus Seizure Resulting from Accidental Injection of Tranexamic Acid in Spinal Anesthesia. Anesth. Analg 108, 1984-1986. doi:10.1213/ane.0b013e3181a04d69

Nam, K. H., Yi, S. A., Nam, G., Noh, J. S., Park, J. W., Lee, M. G., et al. (2019). Identification of a Novel S6K1 Inhibitor, Rosmarinic Acid Methyl Ester, for Treating Cisplatin-Resistant Cervical Cancer. BMC Cancer 19, 773. doi:10.1186/s12885-019-5997-2

Nikolaev, A. I. (1969). The Use of Asparaginase Preparations for the Treatment of Tumors and Leukemia (Review of the Literature). Probl. Gematol Pereliv Krovi $14,51-60$.

Nikonorova, I. A., Mirek, E. T., Signore, C. C., Goudie, M. P., Wek, R. C., and Anthony, T. G. (2018). Time-resolved Analysis of Amino Acid Stress Identifies eIF2 Phosphorylation as Necessary to Inhibit mTORC1 Activity in Liver. J. Biol. Chem. 293, 5005-5015. doi:10.1074/jbc.RA117.001625

O'Grady, R. L., Upfold, L. I., and Stephens, R. W. (1981). Rat Mammary Carcinoma Cells Secrete Active Collagenase and Activate Latent Enzyme in the Stroma via Plasminogen Activator. Int. J. Cancer 28, 509-515. doi:10.1002/ijc.2910280418

Oertli, D., Laffer, U., Haberthuer, F., Kreuter, U., and Harder, F. (1994). Perioperative and Postoperative Tranexamic Acid Reduces the Local Wound Complication Rate after Surgery for Breast Cancer. Br. J. Surg. 81, 856-859. doi:10.1002/bjs.1800810621

Ogawa, H., Sekiguchi, F., Tanaka, N., Ono, K., Tanaka, K., Kinjo, M., et al. (1982). Effect of Antifibrinolysis Treatment on Human Cancer in Nude Mice. Anticancer Res. 2, 339-344.

Pearce, L. R., Alton, G. R., Richter, D. T., Kath, J. C., Lingardo, L., Chapman, J., et al. (2010). Characterization of PF-4708671, a Novel and Highly Specific Inhibitor of P70 Ribosomal S6 Kinase (S6K1). Biochem. J. 431, 245-255. doi:10.1042/ BJ20101024

Pilewskie, M., Ho, A., Orell, E., Stempel, M., Chen, Y., Eaton, A., et al. (2014). Effect of Margin Width on Local Recurrence in Triple-Negative Breast Cancer Patients Treated with Breast-Conserving Therapy. Ann. Surg. Oncol. 21, 1209-1214. doi:10.1245/s10434-013-3416-5

Radosa, J. C., Eaton, A., Stempel, M., Khander, A., Liedtke, C., Solomayer, E. F., et al. (2017). Evaluation of Local and Distant Recurrence Patterns in Patients with Triple-Negative Breast Cancer According to Age. Ann. Surg. Oncol. 24, 698-704. doi:10.1245/s10434-016-5631-3

Rothberg, P. G. (1987). The Role of the Oncogene C-Myc in Sporadic Large Bowel Cancer and Familial Polyposis Coli. Semin. Surg. Oncol. 3, 152-158. doi:10.1002/ssu.2980030305

Ruggero, D. (2009). The Role of Myc-Induced Protein Synthesis in Cancer. Cancer Res. 69, 8839-8843. doi:10.1158/0008-5472.CAN-09-1970

Saksela, K. (1990). Myc Genes and Their Deregulation in Lung Cancer. J. Cel Biochem 42, 153-180. doi:10.1002/jcb.240420306 
Shiu, R. P., Watson, P. H., and Dubik, D. (1993). c-Myc Oncogene Expression in Estrogen-dependent and -independent Breast Cancer. Clin. Chem. 39, 353-355. doi:10.1093/clinchem/39.2.353

Soma, H., Sashida, T., Yoshida, M., Miyashita, T., and Nakamura, A. (1980). Treatment of Advanced Ovarian Cancer with Fibrinolytic Inhibitor (Tranexamic Acid). Acta Obstet. Gynecol. Scand. 59, 285-287. doi:10.3109/ 00016348009155415

Stonelake, P. S., Jones, C. E., Neoptolemos, J. P., and Baker, P. R. (1997). Proteinase Inhibitors Reduce Basement Membrane Degradation by Human Breast Cancer Cell Lines. Br. J. Cancer 75, 951-959. doi:10.1038/bjc.1997.166

Suojanen, J., Sorsa, T., and Salo, T. (2009). Tranexamic Acid Can Inhibit Tongue Squamous Cell Carcinoma Invasion In Vitro. Oral Dis. 15, 170-175. doi:10.1111/j.1601-0825.2008.01507.x

Tanaka, N., Ogawa, H., Kinjo, M., Kohga, S., and Tanaka, K. (1982). Ultrastructural Study of the Effects of Tranexamic Acid and Urokinase on Metastasis of Lewis Lung Carcinoma. Br. J. Cancer 46, 428-435. doi:10.1038/bjc.1982.220

Thamilselvan, V., Craig, D. H., and Basson, M. D. (2007). FAK Association with Multiple Signal Proteins Mediates Pressure-Induced colon Cancer Cell Adhesion via a Src-dependent PI3K/Akt Pathway. FASEB J. 21, 1730-1741. doi:10.1096/fj.06-6545com

Turner, B. M. (2000). Histone Acetylation and an Epigenetic Code. Bioessays $22, \quad 836-845 . \quad$ doi:10.1002/1521-1878(200009)22:9<836:AIDBIES9>3.0.CO;2-X

Tweedie-Cullen, R. Y., Brunner, A. M., Grossmann, J., Mohanna, S., Sichau, D., Nanni, P., et al. (2012). Identification of Combinatorial Patterns of posttranslational Modifications on Individual Histones in the Mouse Brain. PLoS One 7, e36980. doi:10.1371/journal.pone.0036980

van Gils, N., Martiañez Canales, T., Vermue, E., Rutten, A., Denkers, F., van der Deure, T., et al. (2021). The Novel Oral BET-CBP/p300 Dual Inhibitor NEO2734 Is Highly Effective in Eradicating Acute Myeloid Leukemia Blasts and Stem/Progenitor Cells. Hemasphere 5, e610. doi:10.1097/ hs 9.0000000000000610

Varshosaz, J., and Anvari, N. (2018). Enhanced Stability of L-Asparaginase by its Bioconjugation to Poly(styrene-Co-Maleic Acid) and Ecoflex Nanoparticles. IET Nanobiotechnol 12, 466-472. doi:10.1049/iet-nbt.2017.0156

Wang, M., Ferreira, R. B., Law, M. E., Davis, B. J., Yaaghubi, E., Ghilardi, A. F., et al. (2019a). A Novel Proteotoxic Combination Therapy for EGFR+ and HER2+ Cancers. Oncogene 38, 4264-4282. doi:10.1038/s41388-019-0717-6

Wang, M., Law, M. E., Davis, B. J., Yaaghubi, E., Ghilardi, A. F., Ferreira, R. B., et al. (2019b). Disulfide Bond-Disrupting Agents Activate the Tumor Necrosis Family-Related Apoptosis-Inducing Ligand/death Receptor 5 Pathway. Cell Death Discov. 5, 153. doi:10.1038/s41420-019-0228-9

Wang, Y. M., Gu, M. L., Meng, F. S., Jiao, W. R., Zhou, X. X., Yao, H. P., et al. (2017). Histone Acetyltransferase P300/CBP Inhibitor C646 Blocks the Survival and Invasion Pathways of Gastric Cancer Cell Lines. Int. J. Oncol. 51, 1860-1868. doi:10.3892/ijo.2017.4176
Wortmann, A., He, Y., Christensen, M. E., Linn, M., Lumley, J. W., Pollock, P. M., et al. (2011). Cellular Settings Mediating Src Substrate Switching between Focal Adhesion Kinase Tyrosine 861 and CUB-Domain-Containing Protein 1 (CDCP1) Tyrosine 734. J. Biol. Chem. 286, 42303-42315. doi:10.1074/ jbc.M111.227462

Wright, H. J., Arulmoli, J., Motazedi, M., Nelson, L. J., Heinemann, F. S., Flanagan, L. A., et al. (2016). CDCP1 Cleavage Is Necessary for HomodimerizationInduced Migration of Triple-Negative Breast Cancer. Oncogene 35, 4762-4772. doi:10.1038/onc.2016.7

Wu, C. C., Ho, W. M., Cheng, S. B., Yeh, D. C., Wen, M. C., Liu, T. J., et al. (2006). Perioperative Parenteral Tranexamic Acid in Liver Tumor Resection: a Prospective Randomized Trial toward a "blood Transfusion"-free Hepatectomy. Ann. Surg. 243, 173-180. doi:10.1097/ 01.sla.0000197561.70972.73

Yang, H., Pinello, C. E., Luo, J., Li, D., Wang, Y., Zhao, L. Y., et al. (2013). Smallmolecule Inhibitors of Acetyltransferase P300 Identified by High-Throughput Screening Are Potent Anticancer Agents. Mol. Cancer Ther. 12, 610-620. doi:10.1158/1535-7163.MCT-12-0930

Yue, M., Jiang, J., Gao, P., Liu, H., and Qing, G. (2017). Oncogenic MYC Activates a Feedforward Regulatory Loop Promoting Essential Amino Acid Metabolism and Tumorigenesis. Cell Rep 21, 3819-3832. doi:10.1016/j.celrep.2017.12.002

Zhang, H., Zha, X., Tan, Y., Hornbeck, P. V., Mastrangelo, A. J., Alessi, D. R., et al. (2002). Phosphoprotein Analysis Using Antibodies Broadly Reactive against Phosphorylated Motifs. J. Biol. Chem. 277, 39379-39387. doi:10.1074/ jbc.M206399200

Conflict of Interest: Tranexamic Technologies, BL, and RC have pending patent applications related to the results presented herein.

The remaining authors declare that the research was conducted in the absence of any commercial or financial relationships that could be construed as a potential conflict of interest.

Publisher's Note: All claims expressed in this article are solely those of the authors and do not necessarily represent those of their affiliated organizations, or those of the publisher, the editors and the reviewers. Any product that may be evaluated in this article, or claim that may be made by its manufacturer, is not guaranteed or endorsed by the publisher.

Copyright (c) 2022 Law, Davis, Ghilardi, Yaaghubi, Dulloo, Wang, Guryanova, Heldermon, Jahn, Castellano and Law. This is an open-access article distributed under the terms of the Creative Commons Attribution License (CC BY). The use, distribution or reproduction in other forums is permitted, provided the original author(s) and the copyright owner(s) are credited and that the original publication in this journal is cited, in accordance with accepted academic practice. No use, distribution or reproduction is permitted which does not comply with these terms. 